\title{
A Avaliação de Ciclo de Vida (ACV) de Sistemas Construtivos
}

\author{
Cristiane Bueno \\ João Adriano Rossignolo
}

No que toca a avaliação dos sistemas construtivos, a análise dos sistemas existentes para certificaçáo ambiental de edifícios revela que há raras ferramentas que avaliam desempenho ambiental objetivamente por ACV, predominando o reconhecimento de atributos de produtos (custo, durabilidade, renovabilidade, teor reciclado). O problema da abordagem por atributos é que eles são tratados isoladamente e perde-se a noção global do impacto (SILVA, 2007).

Existem diversos métodos e ferramentas para avaliação ambiental, alguns especificamente desenvolvidos como ferramentas de seleção, outros que podem funcionar como tal, mesmo sem terem sido originalmente criados com esse objetivo. A ampliação do leque de preocupaçôes ambientais levou à consideração de emissóes de resíduos e de uso e depleção de recursos naturais, que deveriam ser incorporados em uma estrutura de avaliação mais abrangente. Neste contexto, a ACV emergiu como um método reconhecido e que foi a base para a criação de diversas ferramentas de avaliação. Ao mesmo tempo, a complexidade dos produtos da construção civil, incluindo os materiais, sistemas, subsistemas e as inúmeras possibilidades de combinação desses elementos para a constituição de uma edificação, criou produtos mais complexos do que os bens de consumo que vinham sendo avaliados pela $\mathrm{ACV}$ (JOHN et al., 2006). A fim de analisar o impacto global das medidas de redução de consumo de recursos durante o período de vida de um edifício, a realização de uma avaliação de ciclo de vida do edifício como um todo demonstra ser uma metodologia de grande utilidade (VERBEECK; HENS, 2010b).

A ACV (Avaliação de Ciclo de Vida) é aplicável a todos os níveis do sistema no setor da construção. Duas abordagens principais da ACV para 
tais aplicaçôes podem ser observadas: uma abordagem "de baixo para cima", centrada na seleção de materiais de construção, e uma abordagem "de cima para baixo", que considera todo o edifício como ponto de partida para futuras melhorias (ERLANDSSON; BORG, 2003).

A ACV foi desenvolvida principalmente para a concepção de produtos com baixo impacto ambiental. Como produtos, os edifícios são especiais porque têm uma vida relativamente longa, sofrem constantes alteraçôes, muitas vezes têm funçóes múltiplas, contêm muitos componentes diferentes, são produzidos localmente, são normalmente únicos, causam impacto local, são integrados com a infraestrutura, etc., portanto, as fronteiras de seu sistema não são claras (BRIBIÁN et al., 2009).

Chevalier e Le Teno (1996) listam algumas das hipóteses que devem ser consideradas para a realização de uma ACV e analisam suas consequências sobre o significado dos resultados que elas produzem:

- Estabilidade no tempo: A primeira suposição feita em uma ACV é considerar o sistema de produçáo como um sistema estável no tempo. Essa hipótese permite que se obtenha apenas um retrato instantâneo do ciclo de vida do produto.

- Separabilidade: O método de ACV também assume que o sistema desenhado em torno de um produto é completamente independente de outros produtos fora do sistema.

- Precisáo: Em terceiro lugar, supóe-se que nenhum fluxo pode ter mais de um valor exato.

- Estado de equilíbrio: Na maioria das vezes, o risco não é avaliado na $\mathrm{ACV}$, o pressuposto aqui é o de que o sistema do produto está em estado de equilíbrio.

- Modelo mundial, pontual e contínuo: Supóe-se que todos os fluxos ambientais vem e voltam para a mesma fonte. O modelo de mundo também assume reagir continuamente a solicitaçóes contínuas.

$\mathrm{O}$ desenvolvimento de estudos de ACV em edificaçóes requer algumas alteraçóes devido, entre outros aspectos, às diferenças apresentadas com relação ao ciclo de vida de produtos industriais que envolvem, normalmente, um curto espaço de tempo. Obras de engenharia, ao contrário de produtos com 
vida útil de semanas ou meses, são, em geral, caracterizadas por uma vida útil que se estende por alguns anos, décadas ou mesmo séculos (SOARES et al., 2006). Em virtude do tempo de vida relativamente longo dos produtos de construção, a hipótese de estabilidade no tempo também pode produzir resultados altamente incertos (VERBEECK; HENS, 2010a).

Para minimizar a dificuldade de aplicação das metodologias convencionais de ACV ao setor da construção civil, Chevalier e Le Teno (1996), propuseram alguns requisitos especiais para a ACV de sistemas construtivos:

- Regras especiais de fronteira do sistema devem ser definidas para forçar a separabilidade;

- Processos específicos para sistemas construtivos devem ser modelados;

- A hipótese de estabilidade no tempo deve ser forçada ou cancelada;

- A hipótese de precisão tem que ser cancelada;

- A qualidade dos dados e as relaçóes entre eles devem ser documentadas;

- A lista de estressores de impacto deve ser aberta aos critérios definidos pelo utilizador, de acordo com um processo de negociação bem documentado;

- Assistência deve ser prestada aos utilizadores para gestáo dos resultados;

- Um programa de computador deve ser utilizado para auxiliar todo o processo.

Algumas metodologias internacionais devem ser consideradas por sua grande representatividade de aplicação no âmbito internacional, como é o caso das EPDs (Environmental Product Declarations ou Declaraçôes Ambientais de Produtos).

As EPDs, utilizando a norma francesa NFP01-010 (AFNOR, 2004) e baseando-se na avaliação de ciclo de vida dos materiais, oferecem uma análise ambiental e sanitária dos produtos industrializados, inclusive sistemas construtivos. Essas EPDs foram criadas para permitir a comparação e escolha de produtos, no entanto, apresentam limites de utilização, uma vez que fornecem informações que não permitem a comparação direta para a escolha de componentes de construção, primeiramente, porque os materiais de 
construção em geral, não têm as mesmas funções e as mesmas aplicaçóes em um edifício. Além disso, as informações fornecidas pelas EPDs são complexas demais para serem tratadas "à mão" (LEMAIRE et al., 2007). As EPDs buscam a comparação de sistemas dentro de uma mesma categoria e unidade funcional de construção e então estabelecem uma listagem padrão de critérios de emissão e consumo para a comparação de tais produtos dentro de seu ciclo de vida, de forma a uniformizar sua avaliação.

\section{A Metodologia de ACV}

De acordo com a NBR ISO 14040 (2009a), a ACV é a compilação e a avaliação das entradas, das saídas e dos impactos ambientais potenciais de um sistema de produto ao longo de seu ciclo de vida, considerando esse ciclo de forma holística. A Figura 1 representa esse ciclo, no qual são observados estágios consecutivos e encadeados de um sistema de produto, desde a aquisição ou geração da matéria-prima a partir de recursos naturais até a disposição final.

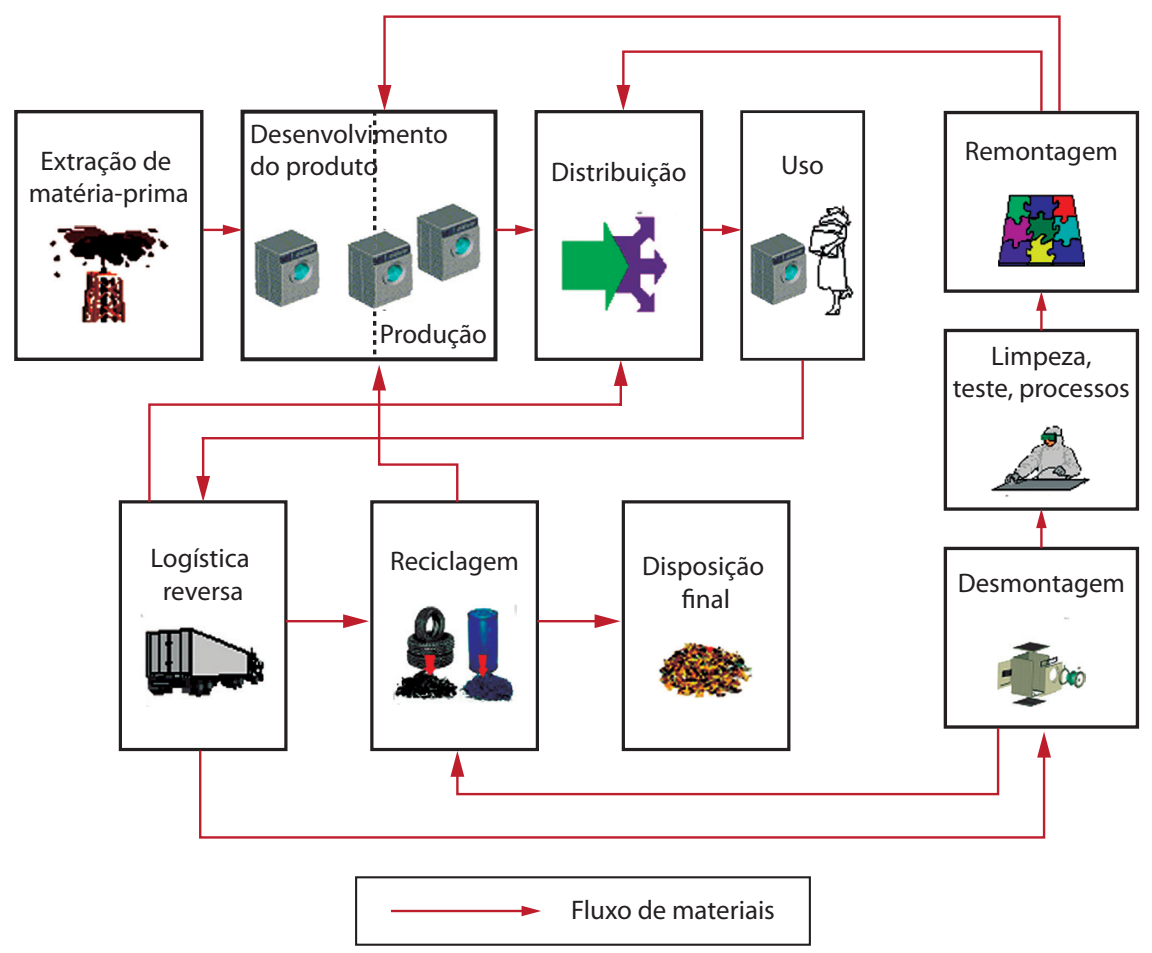

Figura 1. Ciclo de vida do produto. Fonte: Franke (2004). 
Segundo a NBR ISO 14044 (2009b), um estudo de ACV deve ser composto por quatro fases (Figura 2): Definiçāoo de objetivo e escopo; Análise de inventário; Avaliação de impactos; Interpretação.

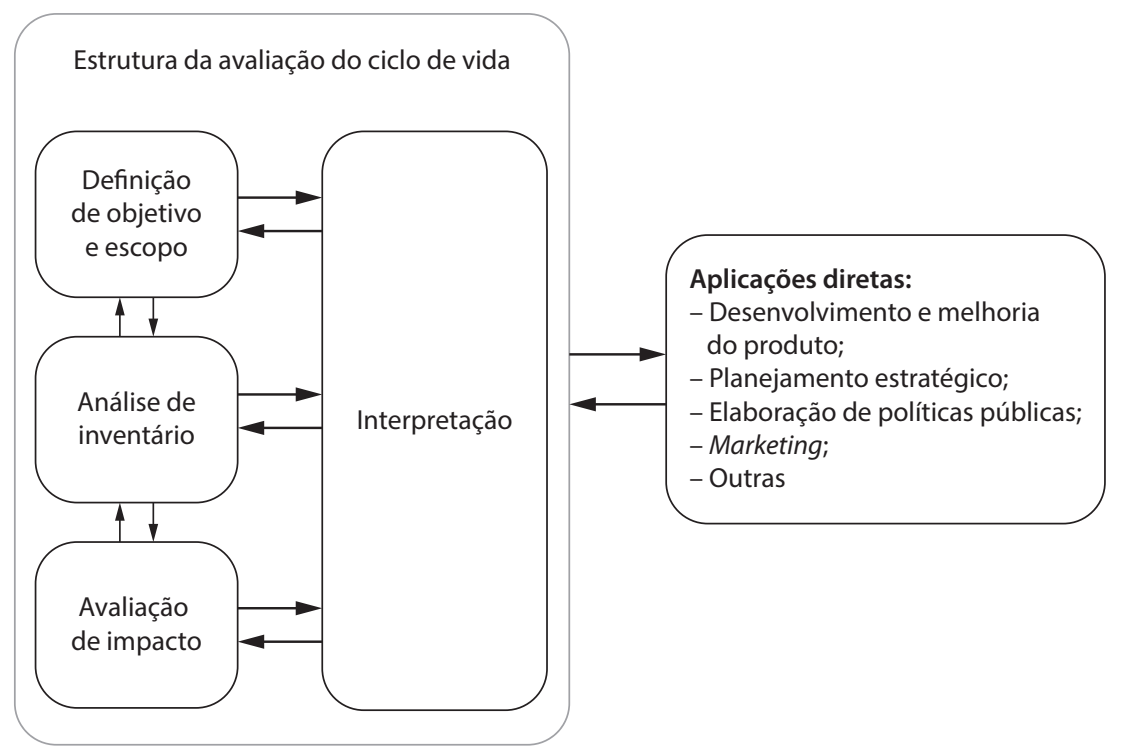

Figura 2. Fases de uma ACV. Fonte: NBR 14040 (2009a).

O escopo de uma ACV, incluindo a fronteira do sistema e o nível de detalhamento, depende do objeto e do uso pretendido para o estudo. A profundidade e a abrangência da ACV podem variar consideravelmente dependendo do objetivo do estudo em particular.

A fase de análise de inventário do ciclo de vida (ICV) é a segunda fase de uma ACV. Trata-se de um inventário dos dados de entrada/saída associados ao sistema em estudo. Essa fase envolve a coleta dos dados necessários para o alcance dos objetivos do estudo em questão.

A fase de avaliação de impacto do ciclo de vida (AICV) é a terceira fase da ACV e tem por objetivo prover informaçóes adicionais para ajudar na avaliação dos resultados do ICV de um sistema de produto, visando ao melhor entendimento de sua significância ambiental.

A interpretação do ciclo de vida é a fase final do estudo de ACV, na qual os resultados de um ICV ou de uma AICV, ou de ambos, são sumarizados e 
discutidos como base para conclusôes, recomendações e tomada de decisão de acordo com a definição de objetivo e escopo.

Neste capítulo, os itens subsequentes serão utilizados para embasamento e detalhamento das fases de um estudo de ACV, o roteiro de aplicação da metodologia proposto pelo ILCD Handbook (EC-JRC, 2010a), que se baseia nas normas ISO 14040 (ABNT, 2009a) e ISO 14044 (ABNT, 2009b). Para a etapa de Avaliação de Impacto de Ciclo de Vida (AICV), as diversas metodologias existentes para avaliação de impacto serão brevemente apresentadas e discutidas com base em informações obtidas no ILCD Handbook (EC-JRC, 2010b).

\subsection{Definição de Objetivo e Escopo}

\subsubsection{Definição do Objetivo}

A definição de objetivos é a primeira fase de qualquer $\mathrm{ACV}$, independentemente se o estudo é limitado ao desenvolvimento de um único conjunto de dados referente a uma unidade de processo ou é um estudo de ACV completo de uma afirmação comparativa para ser publicada.

A definição do objetivo é essencial para todas as outras fases da ACV:

- Orienta todos os aspectos detalhados da definição do escopo, que, por sua vez, define a estrutura para os trabalhos de ACV e ICV;

- O controle de qualidade do trabalho é realizado tendo em vista os requisitos que foram determinados no objetivo do trabalho;

- Se o trabalho vai além de um estudo de ICV, os resultados finais da $\mathrm{ACV}$ são avaliados e interpretados em estreita relação com o objetivo do estudo.

Seis aspectos devem ser abordados e documentados durante a definição dos objetivos:

- Aplicação pretendida dos resultados;

- Limitaçóes devido ao método, suposiçóes e cobertura de impacto;

- Razóes para a realização do estudo e contexto de decisão; 
- Público alvo do estudo;

- Se é um estudo comparativo a ser divulgado ao público;

- Encarregados do estudo e outros atores influentes.

Finalmente, a fim de ajudar na definição do escopo, especialmente em relação à identificação da estrutura de modelagem e da abordagem metodológica do ICV, deve ser realizada uma classificação do contexto de decisão do estudo.

\subsubsection{Aplicações Pretendidas}

Em estudos de apoio à tomada de decisão e contabilidade/monitoramento, muitas vezes, várias aplicaçóes separadas destinam-se a um mesmo estudo ou a aplicação é combinada com o custo, fatores sociais, ou outras informaçóes ambientais complementares. Diferentes aplicaçôes requerem diferentes abordagens metodológicas para a modelagem do ICV.

Estudos puramente metodológicos, sem relação com o suporte à decisão ou contabilidade/controle sobre o objeto de estudo, devem ser explicitados em seu objetivo de forma que náo corra o risco de serem considerados pelo público como uma base para tomada de decisão relativa a produtos.

\subsubsection{Limitações do Método, Suposições e Impactos}

Suposições adotadas ou cobertura de impacto limitada devem ser claramente identificadas e, mais tarde, relatadas de forma proeminente, uma vez que podem interferir diretamente nos resultados do estudo.

Estudos com cobertura de impacto limitada têm restriçóes nas definiçóes iniciais que podem resultar em incapacidade para comparaçóes. Outras insuficiências metodológicas referem-se, por exemplo, às limitaçôes que são inerentes ao $\mathrm{ACV}$ convencional ou às que podem ser causadas pela abordagem específica do método escolhido.

Suposições sobre as características do sistema analisado ou sobre cenários específicos também podem limitar a usabilidade e a reprodutibilidade dos resultados.

Estudos direcionados a nichos de mercado específicos podem diminuir inicialmente os tipos de produtos a serem incluídos no estudo de ACV, 
embora, a partir de uma perspectiva puramente técnica, produtos fora do nicho específico também precisariam ser incluídos para evitar uma comparação potencialmente enganosa.

\subsubsection{Motivos para Realização do Estudo, Contexto de Decisão e Público-alvo}

Definir os direcionadores e motivaçóes do estudo, e, especialmente, identificar o contexto de decisão são passos importantes do estudo. $\mathrm{O}$ contexto de decisão é um critério fundamental para determinar os métodos mais apropriados para o modelo de ICV e também determina diretamente outros aspectos-chave da definiçáo do escopo, das decisóes a serem tomadas durante a coleta de dados e modelagem, do cálculo dos resultados da avaliação de impacto, e, finalmente, para estudos de ACV, também da interpretação dos resultados.

A determinação do público alvo, entre outras coisas, ajuda a identificar as necessidades de revisão crítica e a forma adequada de apresentação do relatório e nível técnico de comunicação.

\subsubsection{Comparações Destinadas a Serem Divulgadas ao Público}

Nos casos em que o estudo de ACV tem como objetivo comparar duas ou mais alternativas para divulgação pública, deve-se manifestar de forma clara que "o estudo inclui uma afirmação comparativa e está previsto para ser divulgado ao público". Esse aspecto implica uma série de requisitos adicionais obrigatórios nos termos da NBR ISO 14040 (ABNT, 2009a) e NBR ISO 14044 (ABNT, 2009b) sobre a execução, revisão de documentação e relatórios do estudo $\mathrm{ACV}$, devido às consequências potenciais dos resultados para, por exemplo, empresas externas, instituiçóes, consumidores, etc.

Ainda, de acordo com a norma ISO 14044 (ABNT, 2009b), um estudo de ICV por si só não deve ser usado para afirmaçôes comparativas destinadas a serem divulgadas ao público.

\subsubsection{Encarregados do Estudo e Outros Atores Influentes}

A definição de objetivo deve identificar quem encomendou o estudo de ACV e todos os seus financiadores. Além disso, outras organizaçóes que 
tenham qualquer influência relevante sobre o estudo devem ser nomeadas, o que inclui os especialistas em ACV que realizarão o estudo.

\subsubsection{Definição do Escopo}

O escopo de um estudo de ICV/ACV é sempre decorrente de seu objetivo, e os seguintes itens do escopo precisam ser claramente definidos:

- Os tipos de entregas do estudo de ACV, alinhados com a aplicação pretendida;

- Os sistemas ou processos que serão estudados e suas funções, unidade funcional, e fluxos de referência;

- Estrutura da modelagem do ICV e forma de manipulação de produtos ou processos multifuncionais;

- Fronteiras do sistema, requisitos de completeza e regras de corte;

- Categorias de impacto da AICV a serem cobertas e seleção de métodos específicos de AICV a serem aplicados, bem como - se incluído normalização e ponderação de dados;

- Outros requisitos de qualidade de dados de ICV com relação à representatividade e adequaçáo geográfica, tecnológica e temporal;

- Tipos, qualidade e fontes das informaçóes e dados requeridos, e, especialmente, a precisão necessária e incertezas máximas permitidas;

- Requisitos especiais para comparaçôes entre sistemas;

- Identificação do mix de energia utilizado para cada um dos processos dentro do ciclo de vida;

- Detalhamento do tipo de transporte utilizado para distribuição dos produtos e transporte de resíduos;

- Descrição dos cenários de fim de vida, gestão de resíduos, etc.;

- Identificação de necessidade de revisão crítica;

- Planejamento do relatório de resultados. 
Dois requisitos transversais no estudo de ACV devem ser considerados devido a sua grande importância: a) Consistência dos métodos, hipóteses e dados; b) Reprodutibilidade.

Todos os métodos e premissas devem ser aplicados de forma suficientemente consistente em todas as fases do ciclo de vida, processos, parâmetros e fluxos do sistema analisado em conformidade com o objetivo do estudo. Isso também se aplica aos métodos de AICV e fatores de ponderação e normalização, se incluídos. Todos os dados do ICV devem ser suficientemente consistentes em termos de exatidão, precisão e integridade, e quaisquer inconsistências devem ser documentadas.

A reprodutibilidade de um estudo de ACV é uma avaliação qualitativa na medida em que a documentação dos métodos, suposiçóes e dados/fontes de dados permitiria que um praticante independente reproduzisse os resultados do estudo e quaisquer conclusôes ou recomendaçóes formuladas.

\subsubsection{Tipos de Entregas e Aplicações Pretendidas}

Os tipos mais comumente produzidos de resultados são os seguintes, dos mais básicos aos mais complexos:

- Estudo de Inventário de Ciclo de Vida (ICV);

- Resultados dos estudos de Avaliação de Impacto de Ciclo de Vida (AICV);

- Modelo detalhado do ICV do sistema analisado.

É importante salientar que estudos comparativos a serem divulgados ao público sempre deverão ser estudos completos de $\mathrm{ACV}$, com todas as suas etapas.

\subsubsection{Função, Unidade Funcional e Fluxo de Referência}

Duas definições muito importantes para o estabelecimento de um estudo de ACV são o "Fluxo de referência" e a "Unidade Funcional".

O fluxo de referência é o fluxo (ou fluxos em caso de processos multifuncionais) ao qual todos os outros fluxos de entrada e de saída quantitativamente se referem, ou seja, é o fluxo quantitativo relativo à unidade funcional definida. 
Unidade Funcional é a unidade de referência para a quantificação do desempenho de um sistema de produto. É com base nessa unidade que será realizado todo o estudo de ACV.

Uma ou mais funções e unidades funcionais mensuráveis de cada um dos sistemas devem ser claramente identificadas. Muitas vezes, o objetivo do estudo de ACV determina qual das funçôes individuais de um sistema estará em foco e qual será o objeto analisado ou se o sistema todo é objeto da análise.

O primeiro passo para a definição da unidade funcional é a identificação e quantificação das propriedades mensuráveis relevantes e do desempenho técnico/funcional do sistema.

Os aspectos qualitativos relevantes também devem ser documentados, uma vez que podem ser decisivos para a aceitação do produto pelos usuários. Isso é necessário para assegurar que os produtos a serem analisados são realmente comparáveis.

A definição da unidade funcional deve, portanto, incluir os aspectoschave quantitativos e qualitativos para evitar subjetividade na definição da equivalência dos produtos. No desenvolvimento de produtos, os conceitos de "propriedades obrigatórias" e "propriedades de posicionamento" são algumas vezes utilizados. As propriedades obrigatórias são características que o produto deve possuir para que o usuário perceba-o como um produto funcionalmente útil (incluindo requisitos legais). As propriedades de posicionamento, por outro lado, são características opcionais que podem ser utilizadas para posicionar o produto no mercado de forma mais atrativa do que outros produtos similares. A definição quantitativa da função do produto (assim como alguns aspectos qualitativos) será tipicamente baseada nas propriedades obrigatórias do produto, enquanto outros aspectos qualitativos, tipicamente relacionados à percepçáo do usuário, podem ser identificados dentre as propriedades de posicionamento.

A definição quantitativa da unidade funcional do produto deve ser baseada em normas técnicas sempre que possível e apropriado. No caso de falta de uma norma técnica aplicável e apropriada, é permitida e requerida a especificação de um meio apropriado, reprodutível e claramente documentado de mensuração da unidade funcional.

Nos casos em que uma unidade funcional relevante não for encontrada, torna-se necessária a identificação quantitativa e qualitativa do fluxo de 
referência, assim como uma descrição detalhada do produto, a fim de que suas características mais relevantes possam ser identificadas.

Em processos multifuncionais, para cada função, uma unidade funcional e fluxo de referência devem ser identificados de forma apropriada, dependendo do tipo de cofuncionalidade. Caso contrário, especificaçóes técnicas do processo e suas funçôes devem ser fornecidas. Para sistemas ou produtos com apenas uma função relevante (sistemas monofuncionais), a unidade funcional deve ser especificada, juntamente com um fluxo de referência, de forma clara e detalhada. Para sistemas multifuncionais com funçôes múltiplas e paralelas, devem ser fornecidas especificações técnicas detalhadas e a unidade funcional correspondente, assim como o fluxo de referência.

\subsubsection{Estrutura de Modelagem do Inventário de Ciclo de Vida (ICV)}

$\mathrm{Na}$ definição de escopo, uma decisão importante deve ser tomada em relação aos princípios e abordagens metodológicas do ICV que serão aplicados na modelagem do sistema. A modelagem pode ser atribucional ou consequencial, e a multifuncionalidade pode ser solucionada por alocação ou expansão/substituição do sistema. Essas escolhas trazem implicaçôes para diversas seleçôes futuras, incluindo a forma como os dados de inventário deverão ser coletados e obtidos.

O modelo atribucional de ciclo de vida retrata sua cadeia de fornecimento real ou prevista, específica ou média, bem como a utilização e fim de vida da sua cadeia de valor. $\mathrm{O}$ sistema existente ou previsto é incorporado a uma tecnosfera estática.

O modelo consequencial de ciclo de vida retrata uma cadeia de fornecimento genérica tal como ela é teoricamente esperada em consequência da decisão analisada. $\mathrm{O}$ sistema interage com os mercados, e essas mudanças são retratadas de forma que uma demanda adicional para o sistema analisado deve ter uma tecnosfera dinâmica que está reagindo com essa demanda adicional. O objetivo é identificar as consequências que uma decisão no sistema em primeiro plano têm em relação a outros processos e sistemas da economia, tanto no sistema de segundo plano como em outros sistemas. O sistema analisado é modelado em torno dessas consequências, assim um passo fundamental na modelagem consequencial é a identificação dos processos marginais. 
Quanto à multifuncionalidade, uma variante dos processos multifuncionais é o produto multifuncional, que é metodologicamente igual, mas normalmente é modelado de forma diferente em conjuntos de dados de ICV: enquanto cada cofunção dos processos multifuncionais anteriormente mencionados tem um fluxo de referência individual, no caso de produtos multifuncionais, normalmente, só um fluxo de referência é usado.

Diferentes abordagenssão utilizadas paraa resolução de multifuncionalidade. A escolha da abordagem mais adequada depende, entre outros fatores, do objetivo do estudo, dados e informaçóes disponíveis e das características do processo ou produto multifuncional.

A forma mais adequada de resolver a multifuncionalidade deve ser identificada já na fase de escopo da $\mathrm{ACV}$, pois afeta a identificação dos dados de inventário e outras informaçóes necessárias. O problema da multifuncionalidade pode ser resolvido pelas seguintes abordagens:

- Subdivisão dos processos multifuncionais - refere-se à coleta de dados individualmente para os processos monofuncionais que se relacionam com o sistema analisado e que estão contidos no processo multifuncional;

- Expansão do sistema (incluindo substituição) - Pode-se resolver a multifuncionalidade expandindo as fronteiras do sistema e substituindo uma função não necessária por uma forma alternativa ou, quando vários sistemas multifuncionais devem ser comparados em um estudo, isso seria feito pela expansão das fronteiras do sistema, pela adição das funçóes faltantes e pelos inventários dos respectivos produtos monofuncionais. Expansão do sistema e substituição são as abordagens metodológicas correspondentes para a solução de multifuncionalidade na modelagem consequencial. Substituição significa subtrair o inventário de outro sistema do sistema analisado. Tal ação leva muitas vezes a fluxos de inventário negativo. Na prática, a expansão do sistema pode levar à necessidade de nova expansão do sistema à medida que os sistemas inclusos muitas vezes são novamente multifuncionais. Isso pode ser resolvido, em muitos casos, por regras de corte.

- Alocação - Resolve a multifuncionalidade pela divisão dos valores das entradas e saídas individuais entre as cofunçôes de acordo com algum critério de alocação. 
Uma combinação específica da estrutura de modelagem do ICV (atribucional ou consequencial) e das abordagens metodológicas de ICV (alocação ou expansão do sistema) é identificada para cada situação de objetivo.

\subsubsection{Obtenção das Fronteiras do Sistema e Critérios de Corte}

As fronteiras do sistema definem quais partes do ciclo de vida e quais processos pertencem ao sistema analisado, isto é, são necessárias para a determinação de sua função, conforme definido pela sua unidade funcional. Uma definição precisa de fronteiras do sistema é importante para assegurar que todos os processos atribucionais e consequenciais sejam incluídos no sistema modelado e que todos os impactos ambientais potenciais sejam apropriadamente cobertos. Os níveis de critérios de corte e as incertezas máximas permitidas são as medidas chave para a qualidade geral dos resultados do estudo de ICV/ACV.

A ACV representa impactos relacionados a processos e produtos, mas não cobre, por exemplo, impactos de acidentes, derramamentos e impactos na saúde. Isso porque esses impactos ocorrem na tecnosfera e não estão sujeitos a qualquer destino ambiental e da cadeia de exposição. Se inclusos, eles devem ser inventariados, agregados e interpretados separadamente dos inventários de ciclo de vida, que dizem respeito a interaçóes entre a tecnosfera e a ecosfera. Uma alternativa para a avaliação desses impactos é a aplicação de uma análise de risco, que poderia avaliar a possibilidade de incidência de tais eventos e as possíveis dimensóes de seus impactos.

Para os conjuntos de dados de unidades de processo e fluxos de produtos e resíduos, a fronteira do sistema é aquela entre o processo modelado e o resto da tecnosfera. Para resultados de ICV e de conjuntos de dados de AICV, assim como para ACVs completas, as fronteiras do sistema devem ser determinadas de forma que todos os fluxos que as transpóem sejam exclusivamente fluxos elementares e de referência. Na realidade, mesmo para produtos simples, todas as atividades econômicas são de alguma forma parte do sistema. No entanto, o número de processos que contribuem em grau quantitativamente relevante para o sistema é normalmente bastante limitado. $\mathrm{Na}$ prática, todos os fluxos de produto, de resíduos e elementares que não sejam quantitativamente relevantes ou de referência podem ser ignorados. 
Portanto, definir as fronteiras do sistema significa decidir quais estágios do ciclo de vida, tipos de atividades, processos específicos e fluxos elementares deverão ser inclusos e quais deverão ser ignorados no modelo de ciclo de vida. A definição qualitativa das fronteiras do sistema deve identificar aquelas partes do ciclo de vida que devem ser inclusas. A fronteira do sistema deve ser representada por um diagrama semiesquemático que mostre explicitamente quais partes do sistema e estágios de seu ciclo de vida estão inicialmente destinados a serem incluídos e excluídos.

A exclusão sistemática de transportes, infraestrutura, serviços, atividades administrativas, entre outros não é apropriada a menos que seja necessária de acordo com objetivos específicos do estudo de ACV. A necessidade de inclusão e possibilidade de exclusão de atividades apenas pode ser decidida para um dado caso tendo em vista o atendimento de requisitos de completeza e precisão dos resultados.

O critério quantitativo de corte define o valor de corte a ser aplicado para produtos, resíduos e fluxos elementares que cruzam a fronteira do sistema analisado, mas que não são quantitativamente incluídos no inventário. Em geral, todos os processos e fluxos que são atribuíveis ao sistema analisado devem ser incluídos nas fronteiras do sistema. Entretanto, nem todos esses processos e fluxos elementares são quantitativamente relevantes. Para os menos relevantes, dados de menor qualidade ou estimados podem ser usados, diminuindo os esforços para coleta e obtenção de dados de alta qualidade para aquelas partes. A definição quantitativa das fronteiras do sistema diz respeito à omissão admissível de estágios inteiros do ciclo de vida, tipos de atividades, processos e produtos específicos e fluxos elementares. Essas omissóes, entretanto, apenas podem ser justificadas se forem insignificantes para o resultado do estudo. Ao lado do fluxo de referência que fornece a unidade funcional e fluxos de resíduos permitidos, nenhum outro fluxo relevante deve atravessar a fronteira entre o sistema analisado e o resto da tecnosfera, na medida do possível. E apenas os fluxos elementares devem cruzar a fronteira entre o sistema analisado e da ecosfera.

Os componentes de qualidade de dados interagem de forma multiplicativa e, tipicamente, os dados de qualidade mais fraca acabam por diminuir a qualidade geral dos dados. Portanto, um critério válido de corte deve ser definido baseando-se no grau quantitativo de completeza dos impactos ambientais gerais do sistema do produto. 


\subsubsection{Preparação do Embasamento para a Avaliação de Impacto}

A Avaliação de Impacto de Ciclo de Vida (AICV) agrega os dados obtidos nos inventários de forma a facilitar sua interpretação. Opcionalmente, a normalização e ponderação de tais dados também podem ser aplicadas para dar suporte a tal interpretação. Ao mesmo tempo, a avaliação de impacto também é necessária para o estabelecimento de critérios de corte e para avaliação de completeza.

As categorias de impacto ambiental cobertas na $\mathrm{AICV}$, assim como as metodologias de AICV, normalização, agrupamento e ponderação, devem ser determinadas anteriormente à analise inicial do inventário para assegurar que dados relevantes sejam coletados.

Uma análise baseada em ICV, sem avaliação de impacto, pode, em alguns casos, ser justificada, dependendo do objetivo do estudo. Entretanto, é importante notar que esse tipo de análise pode limitar a interpretação dos resultados e comparaçóes. Por esse motivo, em caso de estudos comparativos a serem divulgados ao público, afirmações baseadas apenas em ICV não são permitidas, de acordo com a norma NBR ISO 14044 (ABNT, 2009b).

A seleção das categorias de impacto deve ser completa, abrangendo todas as questóes ambientais relevantes relacionadas ao sistema analisado. Dependendo da aplicação pretendida, pode ser decidido, durante a definição de objetivo, trabalhar com uma seleção limitada de categorias de impacto ambiental. A exclusão inicial de categorias de impactos relevantes deve ser claramente documentada e considerada na interpretação dos resultados, pois pode limitar consideravelmente as conclusóes e recomendaçóes do estudo.

Dependendo do objetivo do estudo e da natureza do sistema estudado, a inclusão de categorias ou fatores de impacto faltantes, que sejam relevantes para os resultados finais, pode ser necessária. Além disso, para estudos comparativos de ACV, também é importante que a adequação de metodologias genéricas de AICV seja discutida na fase de interpretação do estudo.

A normalização e agrupamento, de acordo com as normas NBR ISO 14040 (ABNT, 2009a) e NBR ISO 14044 (ABNT, 2009b), são estágios opcionais, que visam a apoiar a interpretação do perfil de impacto, de forma a buscar um resultado completamente agregado. A fase de agrupamento exige 
a normalização prévia, uma vez que o agrupamento sem prévia normalização pode fornecer resultados "mascarados".

Nos casos de afirmações comparativas a serem divulgadas ao público, assim como todos os outros estudos que visam a apoiar comparação de produtos por terceiros, a seleção final dos métodos de AICV a serem aplicados, tal como os níveis de avaliação (de ponto intermediário ou final), deve ser feita durante a definição inicial do escopo, da mesma forma que as decisóes a respeito da possibilidade de inclusão das fases de normalização e agrupamento. Tais decisóes devem ser documentadas de forma que permitam que, em uma futura revisão crítica, possa ser verificado o momento em que tais decisóes foram tomadas.

\subsubsection{Representatividade e Adequação dos Dados do ICV}

Para que os dados de inventário possam representar de forma válida os impactos ambientais de um sistema, eles devem ter representatividade e adequação. A representatividade está relacionada à capacidade dos dados coletados representarem o inventário real do processo, abrangendo a coleta de dados relacionados à tecnologia, a geografia e o tempo. A adequação se refere ao grau em que os dados utilizados no modelo do sistema realmente representam o verdadeiro processo do sistema analisado.

A representatividade tecnológica de um processo ou sistema identifica quão bem os dados de inventários representam esse sistema/processo em relação às reais características técnicas ou tecnológicas documentadas nas informaçóes descritivas do relatório.

Para o modelo atribucional, dados específicos relacionados à tecnologia da cadeia de fornecimento devem ser previstos para o sistema de primeiro plano, e médias do consumo de mercado, para o sistema de fundo. Esses são idealmente os dados primários e secundários dos fornecedores e dos usuários. Para o modelo consequencial, os mesmos dados devem ser previstos para o sistema de primeiro plano, incluindo-se as informaçôes específicas de tecnologia de fornecedores para ligaçóes contratualmente fixas ou planejadas da cadeia de fornecimento. As tecnologias marginais de curto ou longo prazo devem ser previstas para serem usadas no sistema de fundo.

A representatividade geográfica de um processo ou sistema identifica quão acuradamente os dados de inventário representam a localizaçáo do processo/ 
sistema em relação à sua operação, produção ou consumo. A abrangência geográfica dos dados de ICV deve representar a menor unidade geográfica apropriada, dependendo do objetivo do estudo e das aplicaçóes pretendidas.

A necessidade de representatividade temporal é muito influenciada pela aplicação pretendida do estudo e seus requisitos em relação, por exemplo, à validade futura dos resultados e conclusóes da ACV.

\subsubsection{Tipos, Qualidade e Fontes dos Dados e Informações Requeridos}

Durante a definição inicial de escopo e a preparação do trabalho subsequente, os principais tipos e fontes de dados e outras informaçóes devem ser identificados, os quais serão mais detalhados e frequentemente revisados durante as fases iterativas de coleta de dados e modelagem de inventário, avaliação de impacto e interpretação. É recomendado preparar uma visão geral dos principais tipos de dados e informaçóes que serâo necessários, dependendo do tipo de entrega do estudo e determinar os requisitos gerais de dados e sua qualidade.

\subsubsection{Comparação Entre Sistemas}

Estudos envolvendo afirmações comparativas a serem divulgadas ao público devem atender requisitos adicionais para que tais comparaçôes sejam válidas, justas e não enganosas. Isso reflete as consequências que o uso comparativo de resultados de ACV pode ter para outras empresas, instituiçóes e partes interessadas, que não estão diretamente envolvidas no estudo.

Dois aspectos relacionados à questão do que está sendo comparado são importantes para esse tipo de estudo: a equivalência da unidade funcional das alternativas comparadas e a seleçáo não enganosa das alternativas.

Frequentemente, o contexto de aplicação dos produtos comparados também deve ser considerado como parte da unidade funcional, uma vez que produtos com a mesma unidade funcional geral podem ter desempenhos diferentes.

Dentre as propriedades de posicionamento, a durabilidade do produto tem um papel especial, estando diretamente relacionada à unidade funcional do produto. Por isso, a durabilidade deve ser considerada quantitativamente, usando-se a vida útil técnica das alternativas como base para afirmações 
comparativas. Outras consideraçóes sobre vida útil devem ser ponderadas na análise de cenários, como a vida útil de moda, a mecânica, a integridade, a inovação técnica, os custos, etc.

Assegurar a consistência dos métodos, pressupostos e dados usados no estudo de ACV para todos os sistemas comparados é de grande importância. Em estudos de comparação de sistemas, os requisitos gerais de qualidade de dados dependem da diferença relativa do impacto ambiental global entre os sistemas comparados. Nesses casos, com respeito à completeza, os critérios de corte devem ser aplicados para avaliação de impacto, mas também para massa e energia.

Estudos comparativos com base em indicadores ou categorias de impacto selecionadas devem destacar que a comparação não é adequada para identificar alternativas ambientais preferíveis, uma vez que só abrangem os impactos considerados.

\subsubsection{Identificação da Necessidade de Revisão Crítica}

Uma revisão crítica deve ser realizada por peritos que não estão envolvidos no estudo de ACV. Isso é geralmente benéfico para a qualidade e credibilidade, assim como para o valor do estudo. O tipo de revisão crítica requerida depende das aplicações pretendidas do estudo. É útil que, já durante a definição do escopo, seja decidido se uma revisão crítica será feita, por quem e de que forma será realizada. Essa decisão antecipada permite que a coleta de dados, documentação e relatório do estudo sejam adaptados para atender os requisitos da revisão, diminuindo o esforço global.

\subsubsection{Planejamento da Comunicação do estudo}

O relatório do estudo é um elemento vital de qualquer ACV. Sem documentação clara e efetiva para peritos e comunicação para os tomadores de decisão, as ACVs podem tornar-se subjetivas, acarretando em um uso errôneo e enganoso e náo contribuindo para o melhoramento do desempenho ambiental. O relatório deve ser objetivo e transparente, e deve ficar claro o que foi ou não incluso no estudo, e quais conclusóes e recomendaçóes os resultados do estudo podem embasar. É importante que o relatório reflita claramente o estudo, podendo ter diferentes formas e níveis, dependendo de seus objetivos inicialmente estabelecidos. 


\subsection{Análise de Inventário de Ciclo de Vida (ICV)}

Os dados coletados durante a fase de inventário alimentarão todas as fases subsequentes do estudo de $\mathrm{ACV}$, assim como servirão de feedback para as definições estabelecidas nas fases de objetivo e escopo, proporcionando parâmetros mais concretos para o ajuste dessas etapas. Assim, nessa fase, deve ser realizada a coleta de dados e modelagem do sistema, sempre de acordo com as definições do objetivo e escopo do estudo. É por esse motivo que essa é a fase que mais requer esforço e recursos em um estudo de ACV.

A fase de inventário envolve a coleta de dados para:

- Fluxos de entrada e saída dos processos: a) Fluxos elementares (como uso de recursos e emissóes, mas também outras intervenções na ecosfera, como o uso do solo); b) Fluxos de produtos (bens e serviços que se apresentem como produtos de um processo e como entradas/insumos de outro) que liguem o processo analisado a outros processos ; c) Fluxos de resíduos (água residual, resíduos sólidos e efluentes) que precisam ser ligados ao processo de gerenciamento de resíduos para assegurar uma modelagem completa dos esforços relacionados e impactos ambientais;

- Outras informaçôes identificadas na definição de escopo como relevantes para o sistema analisado incluem dados estatísticos, características de processos e produtos e todos os outros dados e informaçóes, exceto aqueles diretamente relacionados à avaliação de impacto.

O tipo específico de trabalho a ser desenvolvido no inventário de ciclo de vida depende das entregas pretendidas do estudo. Ademais, nem todos os passos são requisitos para todo tipo de estudo. Dito isso, o trabalho de inventário de ciclo de vida, em geral, significa:

- Identificação de processos do sistema (modelagem atribucional ou consequencial);

- Planejamento da coleta de dados primários e conjuntos de dados de fontes secundárias;

- Coleta de dados do sistema de primeiro plano para os processos requeridos; 
- Desenvolvimento genérico de dados de ICV, especialmente nos quais os dados médios ou específicos não estão disponíveis e não podem ser desenvolvidos tipicamente por restriçôes de acesso aos dados ou de orçamento;

- Obtenção de dados complementares, como processos da unidade ou resultados de conjuntos de dados de ICV de provedores de dados;

- Média dos dados de ICV ao longo do processo ou produto, incluindo para produçáo em desenvolvimento, fornecimento e consumo;

- Modelagem do sistema pela conexáo e dimensionamento dos conjuntos de dados corretamente, provando que tal sistema realmente fornece a unidade funcional estudada;

- Resoluçáo de problemas de multifuncionalidade nos processos no sistema;

- Cálculo dos resultados do ICV, isto é, realização da somatória de todas as entradas e saídas para todos os processos dentro das fronteiras do sistema. Se totalmente modelado, apenas os fluxos de referência e fluxos elementares deverão permanecer no inventário.

\subsubsection{Identificação de Processos Dentro das Fronteiras do Sistema}

A fronteira do sistema do produto, em um estudo de ACV, inclui ainda, por exemplo, processos de mineração, processamento, manufatura, uso, reparos e manutenção, assim como transporte, tratamento de resíduos e outros serviços adquiridos, como os serviços legais e de limpeza, marketing, produção e desativação de bens de capital, operação das instalaçôes, tais como varejo, armazenamento, escritórios de administração, deslocamentos de pessoal, viagens de negócios, etc. Resumindo, todas as atividades não acidentais que são realizadas de forma relacionada ao sistema analisado e que podem também ser atribuídas a ele (modelagem atribucional) ou esperadas/modeladas como uma consequência de uma decisão do sistema de primeiro plano (modelagem consequencial) devem ser incluídas nas fronteiras do sistema, a menos que sejam quantitativamente irrelevantes pela determinação dos critérios de corte aplicados. 
A maneira como processos são identificados com as fronteiras do sistema diferem consideravelmente entre as modelagens atribucional e consequencial, pois diferentes processos e dados são requeridos com base na abordagem de modelagem.

\subsubsection{Identificação de Processos na Modelagem Atribucional}

A modelagem atribucional retrata o sistema da forma como ele pode ser observado/mensurado, ligando processos únicos dentro da tecnosfera ao longo dos fluxos de matéria, energia e serviços. Essa fase de "atribuição" é crucial, mas está apenas implicitamente abordada nas NBR ISO 14044 (ABNT, 2009b). Diferentes abordagens têm sido desenvolvidas na prática, resultando em fronteiras de sistema, modelos e resultados finais inconsistentes.

Observando a identificação em uma perspectiva mais funcional/técnica, as seguintes fases e processos devem ser, em princípio, atribuídos ao sistema ou processo analisado, começando pela unidade funcional e fluxo de referência do sistema:

- Processo ou sistema central analisado: processo do sistema de primeiro plano que fornece diretamente a unidade funcional ou fluxo de referência analisado como sua função (alguns desses processos são bens, enquanto outros são serviços ou sistemas produto-serviço);

- Incorporação física do bem: bens que fisicamente (de forma parcial ou completa) terminam no bem analisado ou em outros bens que são parte do sistema;

- Contato com o processo central ou bem analisado: bens e serviços que apenas tocam o bem ou processo central, executando uma função de apoio que suporta a prestação da função analisada;

- Serviços para o processo ou sistema central: processos que nem mesmo tocam o processo/bem analisado ou exercem uma funçáo direta para a prestação de um serviço, mas que são requeridos, no entanto, para trabalhar em segundo plano em relaçáo ao processo. Além disso, chegamos a processos marginais que, na verdade, não se relacionam diretamente com o processo ou sistema central. Esses processos indiretos são identificados e se conectam ao sistema de primeiro plano. É importante notar que isso não resulta numa lista interminável de 
processos a serem incluídos, pois pela aplicaçáo de regras de corte com base na experiência em processos semelhantes e julgamento de especialistas - a maioria das etapas pode ser excluída.

Especialmente para processos do sistema de primeiro plano, uma descrição inicial é requerida. Isso irá ser revisado no momento da coleta e documentação dos dados do processo da unidade

\subsubsection{Identificação de Processos na Modelagem Consequencial}

A modelagem consequencial de ICV busca a identificação das consequências de uma decisão no sistema de primeiro plano em outros processos e sistemas da economia e constrói um sistema a ser analisado em torno de tais consequências. Essas consequências são aqueles processos que assumimos serem operados como uma reação à decisão em questáo.

Para identificar as consequências detalhadas e processos marginais, além da expertise em ACV, as seguintes expertises são necessárias, dependendo dos mecanismos e modelos considerados na modelagem consequencial:

- Experiência de previsão de desenvolvimento de tecnologia (curvas de aprendizagem, curvas de experiência);

- Desenvolvimento de cenários;

- Custo e previsóes de mercado;

- Modelagem de custos de tecnologia;

- Modelagem de equilíbrio geral;

- Modelagem de equilíbrio parcial.

Os seguintes itens explicam os passos apropriados à modelagem de consequências para o modelo consequencial:

- O primeiro passo no sentido de identificar os processos marginais que fornecem a função e os processos suplantados é identificar/decidir quais as consequências primárias e secundárias e as restrições que devem ser integradas ao modelo;

- Em seguida, está a identificação dos processos que são operados ou deslocadas devido às consequências identificadas; 
- Por último, realiza-se a análise das consequências consideradas e, tendo em conta as limitaçóes selecionadas, a identificação dos processos e modelagem do ciclo de vida consequencial. Isso começa a partir da decisão analisada no sistema de primeiro plano.

Devem ser avaliadas a necessidade da inclusão das seguintes consequências a menos que elas já sejam explicitamente requeridas ou diretamente derivadas de um objetivo específico do estudo):

- Processos que sejam operados como consequência direta de mercado da decisão para alcançar a demanda adicional de um produto;

- Processos que suplantem/complementem cofunçóes de processos multifuncionais que estejam dentro da fronteira do sistema (em casos de resolução de multifuncionalidade por substituição).

As seguintes consequências são secundárias, mas podem ser avaliadas para serem incluídas na análise:

- Aumento na demanda geral por uma cofunçáo náo requerida se seu valor de mercado é reduzido devido à sua disponibilidade adicional em consequência secundária de uma demanda adicional pela função analisada;

- Efeito de incentivo ao processo para aumentar sua eficiência como consequência secundária de um preço maior para sua cofunção determinante em consequência de aumento de demanda;

- Diminuição da demanda por funçôes concorrentes de uma função não requerida como consequência secundária da diminuição de preço desta devido ao aumento de demanda para a cofunção analisada e, portanto, uma disponibilidade adicional de sua cofunção não requerida;

- Mudanças de comportamento do consumidor.

- Principais passos para identificação de processos no modelo consequencial:

- Considerar as consequências primárias e a dimensão de seu efeito;

- Considerar consequências e limitaçóes secundárias;

- Situação de mercado e competitividade; 
- Identificação da mistura de processos/sistemas marginais de longo e curto prazo.

A multifuncionalidade na modelagem consequencial é resolvida de maneira semelhante à modelagem atribucional em um procedimento de dois passos relacionados à subdivisão, incluindo a consideração de: a) causalidade física, em casos de produção combinada real; (b) produção conjunta, substituição em casos gerais de multifuncionalidade ou substituição em modelos de fim de vida ou tratamento de resíduos.

Especialmente para processos do sistema de primeiro plano, uma descrição inicial é requerida e será revisada no momento da coleta e documentação dos dados do processo da unidade.

\subsubsection{Planejamento da Coleta de Dados}

Antes que o planejamento real da coleta dos dados e informaçóes possa ser realizado, é recomendado obter clareza em algumas opçóes e consideraçóes, a saber:

- Para o sistema de primeiro plano serão coletados dados específicos, médios ou genéricos?

- Necessidade de dados médios multianuais ou dados genéricos;

- Definição das fontes de dados primárias e secundárias;

- Principal foco para concentração de esforços de coleta.

É importante identificar para quais processos do sistema analisado terão de ser desenvolvidos novos estudos específicos do processo da unidade com dados primários e secundários de produtores ou operadores. Esse é tipicamente o caso empregado para o sistema de primeiro plano completo. $\mathrm{O}$ uso de processos técnicos ou diagramas de fluxos é recomendado.

O próximo passo é identificar para quais partes do sistema analisado o uso de conjuntos de dados de ICV médios ou genéricos é mais apropriado. É importante notar que, para um determinado caso, dados médios ou genéricos podem ser mais acurados, completos e precisos, também para alguns processos do sistema de primeiro plano. Se tais dados forem usados, isso precisa ser justificado. 
É recomendado identificar sistematicamente fontes de dados e informaçóes necessários. Isso inclui considerar trabalhar para o sistema de fundo, principalmente com resultados de ICV ou com conjuntos de dados de unidade de processo, os quais têm vantagens e desvantagens que devem ser avaliadas para o caso em questão. Combinaçóes são possíveis se os dados forem consistentes. Dentre as fontes de dados de ICV, as fontes primárias e secundárias podem ser diferenciadas. O princípio orientador deve ser a disponibilidade e a qualidade dos dados mais apropriados. Trabalhar com conjuntos bem documentados e dados já revisados é recomendado, pois isso apoia um uso correto dos conjuntos de dados, uma documentação marginal do sistema analisado e sua revisão.

Um passo importante é avaliar, ao longo do objetivo do estudo, em que pontos dados médios multianuais e genéricos podem ser preferíveis a dados médios anuais, por representarem melhor o processo/sistema. Isso se aplica para processos com fortes variaçóes interanuais no intuito de assegurar uma representatividade temporal suficiente.

Recomenda-se orientar o esforço de coleta de dados pela relevância dos respectivos dados e informaçóes, e basear-se na experiência existente, que reflete o processo ou sistema suficientemente analisado.

\subsubsection{Coleta de Dados de ICV da Unidade de Processo}

Para todos os processos identificados, os dados de inventário devem ser coletados. Uma coleta real de dados de inventário é tipicamente requerida apenas para o sistema de primeiro plano, enquanto todos os dados para o sistema de segundo plano podem ser buscados em bases de dados disponíveis. Os dados da unidade do processo são a base para todo o trabalho de ICV. Idealmente, eles devem estar relacionados a operaçóes individuais para um processo específico, entretanto, esses dados podem também ser referentes às médias para esses processos ou podem ser genéricos e, portanto, retratar um processo ou tecnologia de forma geral em vez de sua operação específica.

\subsubsection{Coleta de Dados Básicos para as Unidades de Processos}

Recomendaçôes são dadas para a coleta de dados primários básicos e sobre a forma de obtê-los: 
- Evitar processos de unidade "caixa preta" (isto é, processos de unidade para os quais os dados coletados são uma combinaçáo de mais de um processo fisicamente separado em passos do processo) por subdivisão ou subdivisão virtual.

- Descrição do que o processo da unidade representa em relação à: (a) tecnologia, geografia e tempo, e qualquer possível limitação de representatividade; (b) Fluxo de referência e unidade funcional.

- Tipos de fluxos de entrada e saída a serem coletados: se possível, dados quantitativos de todas as entradas e saídas relevantes que sáo associados ao processo da unidade devem ser coletados/modelados. Nos casos em que isso não for possível, as lacunas devem ser documentadas no relatório sobre qualidade de dados e na interpretação dos resultados do estudo. Esses fluxos tipicamente incluem: (a) entradas de produtos consumidos, como fluxos de produtos; (b) Entrada de resíduos, como fluxos de resíduos; (c) Entrada de recursos naturais, como fluxos elementares; (d) Emissôes para o ar, água e solo, como fluxos elementares; (e) Outras entradas e saídas que intervêm na ecosfera, como fluxos elementares; (f) Saída de resíduos, como fluxos de resíduos; (g) Saída de bens e serviços de valor agregado fornecidos pelo processo, como fluxos de produtos.

- Os tipos de dados primários: (a) Dados medidos coletados por operadores do processo devem ser preferíveis se possível e apropriado (não apenas dados fisicamente medidos, mas também provenientes de listas de consumo, contas, etc.); (b) Composiçãa e conteúdo energético de produtos e fluxos de resíduos; (c) Vários outros dados podem ser úteis ou até mesmo necessários, como formulaçóes, listas de peças, patentes, engenharia do processo, modelos estequiométricos, especificaçóes e relatórios de testes de produtos e processos, etc.; (d) para modelagem do estágio de uso dos produtos e gerenciamento inicial de resíduos, é recomendado o uso de levantamentos e estudos que analisem o comportamento médio ou típico para complementar as especificaçóes do produto.

- Quantidades do fluxo de referência: é recomendado o uso da quantidade de "uma unidade de referência" do fluxo de referência e expressar o inventário do processo em relação a essa quantidade. 
- Representatividade das condiçóes de operação: Os dados de inventário coletados para um processo específico devem, tanto quanto possível e necessário para alcançar o objetivo do estudo, representar o ciclo operacional completo do processo, incluindo todos os estágios quantitativamente relevantes. Isso se aplica também a serviços, e tal representatividade deve ser documentada. Para mediçóes no processo operado, dados de pelo menos um ano completo devem ser usados para se obter dados médios representativos. Para processos parametrizados, as relaçóes matemáticas devem representar mudanças relevantes do inventário em relação a parâmetros de influência, incluindo relaçóes quantitativas e qualitativas entre fluxos de inventário.

- Verificação de limites legais: É recomendada a verificação da existência de limites legais relevantes para orientação de quais fluxos que devem ser incluídos em quaisquer casos.

- O dimensionamento correto da unidade funcional e do fluxo de referência deve ser assegurado ao converter os dados primários para os fluxos de inventário. Recomenda-se documentar todos os passos efetuados no tratamento dos dados brutos para os fluxos do inventário do processo de unidade.

- Resolução de questóes de confidencialidade: Informaçóes confidenciais ou particulares podem ser protegidas pela agregaçáo dos resultados de ICV e conjuntos de dados do sistema. A transparência pode ser assegurada pela documentação de informaçóes confidenciais em um "relatório confidencial" à parte, acessível apenas para os revisores críticos.

- Uma verificação da validade dos dados coletados deverá ser realizada durante o processo de coleta de dados. Para tal controle de qualidade interino sobre o processo de unidade, recomenda-se aplicar os aspectos técnicos de qualidade dos dados da revisão crítica sobre o alcance e os métodos de revisão.

- Lacunas relevantes de dados de inventário podem ser preenchidas, se possível, por: (a) Identificação da relevância de dados inicialmente faltantes; (b) Se essa triagem mostra que a falta de dados pode ser de importância nas iteraçôes futuras do trabalho de ACV, deve tentar-se, 
primeiro, identificar se o fluxo está realmente acontecendo no processo analisado e então se obter os dados ainda em falta; como segunda opção, estimativas devem ser obtidas; ou, como terceira opção, a lacuna deve ser mantida e comunicada; (c) Para cada novo processo de unidade modelado, quaisquer dados inicialmente faltantes devem ser documentados de forma transparente e consistente; já para julgar a relevância de uma lacuna de dados inicial, é necessário aproximar a exatidão, a precisão e a completeza alcançadas do impacto ambiental total no nível do sistema; as lacunas de dados devem, geralmente, ser preenchidas com dados metodologicamente consistentes, e apenas dados que aumentem a qualidade geral do inventário final para o sistema analisado devem ser usados; (d) Se dados estimados que preencham tais requisitos não estiverem disponíveis, a lacuna de dados deverá ser mantida e documentada.

Recursos não renováveis de energia devem ser inventariados como tipo de recurso energético e em poucos casos (apenas de petróleo primário, secundário, terciário a céu aberto ou de mineração subterrânea de carvão) devem ser diferenciados exclusivamente por tipo de extração de recursos, se essa informação estiver disponível. A relação energia/massa deve ser fornecida para todos os fluxos de recursos energéticos, à exceção de minérios nucleares.

Fontes de energia renováveis devem ser inventariadas como a quantidade de energia utilizável extraída da natureza. Para a biomassa da natureza, esta é a quantidade fisicamente incorporada, medida como valor calorífico inferior de substâncias sem água.

Recursos não devem ser inventariados de forma geograficamente diferenciada e recursos para produção de metais ou outros elementos químicos devem ser inventariados como elementos químicos.

Uso direto e a transformação do solo devem ser inventariados ao longo das necessidades do método de AICV aplicado e se o uso ou transformação do solo forem modelados, dióxido de carbono e outras emissóes e efeitos relacionados também devem ser modelados.

A respeito do uso de água, é recomendado que, pelo menos as entradas (água doce de superfície, águas subterrâneas renováveis, a água subterrânea fóssil/profunda, a água do mar), saídas (emissão / descarga de água em forma líquida, emissóes em forma de vapor) e mudanças na qualidade de água, 
especialmente por substâncias químicas, sejam inventariadas como fluxos elementares separados.

Todas as emissóes e outros fluxos elementares que ocorrem além dos próximos 100 anos da data do estudo de ACV devem ser inventariados separadamente daqueles que ocorrem dentro dos próximos 100 anos.

Tratamentos de resíduos e águas residuais devem ser modelados consistentemente com as fronteiras entre a tecnosfera e a ecosfera; caso contrário, isso deve ser claramente documentado e explicitamente considerado na interpretação subsequente.

Duas exceçôes são resíduos radioativos e resíduos em depósitos subterrâneos, os quais devem ser mantidos como fluxos de resíduos específicos no inventário, a menos que o gerenciamento detalhado a longo prazo e intervençóes relacionadas tenham sido completamente modeladas também para esses casos.

\subsubsection{Seleção de Conjuntos de Dados Secundários de ICV}

Os dados secundários (genéricos, médios ou específicos), para serem usados no modelo do sistema, devem ser metodologicamente consistentes com conjuntos de dados primários que foram especificamente coletados. Conjuntos de dados secundários devem ser selecionados de acordo com sua qualidade de dados em um sentido mais estrito, ou seja, sua representatividade tecnológica, geográfica e temporal, completeza e precisão. Seus fluxos de referência e/ou unidade funcional devem, além disso, ser suficientemente representativos para o processo, bem ou serviço específico que tais dados objetivam representar no sistema analisado.

É recomendado dar preferência a conjuntos de dados com revisão crítica prévia, uma vez que eles limitam o esforço de revisão do sistema analisado. É também indicado dar preferência a conjuntos de dados que estão apoiados por documentação completa e eficientemente organizada.

\subsubsection{Modelagem do Sistema}

Os inventários de todos os processos dentro das fronteiras do sistema devem ser corretamente dimensionados em relação aos demais e à unidade funcional e fluxo de referência do sistema analisado. Nenhum fluxo de produto ou resíduo quantitativamente relevante pode ser deixado sem modelagem 
ou desconectado, com exceção dos fluxos de referência que representem quantitativamente a unidade funcional do sistema. Caso contrário, esses fluxos deverão ser claramente documentados e a lacuna de precisão e completeza resultante deverá ser considerada na interpretação dos resultados.

É recomendado verificar previamente, durante a modelagem, se os conjuntos de dados ou sistema estão propriamente modelados e se atendem aos requisitos de qualidade identificados na fase de escopo.

Lacunas de dados devem ser preenchidas com conjuntos de dados metodologicamente consistentes, enquanto lacunas com pouca relevância podem também ser preenchidas com conjuntos de dados desenvolvidos pelas orientaçóes do ILCD Handbook (EC-JRC, 2010a) que atendam os requisitos gerais de qualidade.

\subsubsection{Cálculo dos Resultados do ICV}

Dependendo do nível de agregação requerido para as aplicações previstas, os inventários de todos os processos inclusos devem ser dimensionados de acordo com sua participação no sistema geral do produto e agregados em, por exemplo, estágios do ciclo de vida ou do sistema do produto completo.

Os mesmos procedimentos de cálculo devem ser aplicados consistentemente no sistema analisado, no momento da agregaçáo dos processos dentro das fronteiras do sistema, para obtenção dos resultados do ICV. É necessário: (a) determinar, para cada processo dentro da fronteira do sistema, quanto de seu fluxo é requerido para o sistema emitir sua unidade funcional e/ou fluxo de referência; (b) dimensionar o inventário de acordo com cada processo; (c) somar os inventários corretamente dimensionados de todos os processos dentro da fronteira do sistema; (d) Se a aplicação pretendida dos resultados requer uma avaliação de impacto de localidade não genérica, a agregação dos fluxos elementares relacionados à localidade deve ser evitada no cálculo dos resultados; (e) Se dados desagregados não puderem ser publicamente apresentados, é recomendado prever a realização da avaliação de impacto no nível desagregado, fornecendo os resultados de AICV juntamente com os resultados agregados de ICV.

Quaisquer fluxos de produtos e resíduos que permaneçam no inventário e que sejam fluxos não funcionais devem ser salientados no relatório e/ou conjunto de dados. Eles também precisam ser modelados mais tarde para o 
uso do conjunto de dados, ou entáo esta lacuna precisa ser explicitamente considerada na interpretação e conclusão subsequentes do estudo.

\subsection{Avaliação de Impacto de Ciclo de Vida (AICV)}

O objetivo da AICV, segundo ABNT (2008), é avaliar o sistema de produto sob uma perspectiva ambiental com o uso de categorias de impacto e de indicadores de categoria associados aos resultados do ICV. Para Udo de Haes et al. (2002), essa fase avalia a significância das intervençôes ambientais contidas no inventário do ciclo de vida. A AICV agrega os dados obtidos nos inventários de forma a facilitar sua interpretação.

Segundo a NBR ISO 14044 (2009b), as etapas obrigatórias da avaliação de impacto do ciclo de vida são:

- Seleção das categorias de impactos;

- Classificação dos aspectos nos impactos, de acordo com sua importância;

- Caracterização pela valoraçáo do aspecto, de acordo com sua magnitude em relação ao impacto.

Adicionalmente, há os elementos opcionais para a normatização, o agrupamento e a ponderação dos resultados dos indicadores e técnicas de análise da qualidade dos dados. O nível de detalhes, a escolha dos impactos avaliados e os métodos dependem do objetivo e do escopo do estudo.

A seleção das categorias de impacto deve ser completa, abrangendo todas as questôes ambientais relevantes relacionadas ao sistema analisado. Dependendo da aplicação pretendida, pode ser decidido durante a definição de objetivo trabalhar com uma seleção limitada de categorias de impacto ambiental. A exclusão inicial de categorias de impacto relevantes deve ser claramente documentada e considerada na interpretação dos resultados, pois pode limitar consideravelmente as conclusóes e recomendações do estudo.

Existem métodos de AICV para "pontos intermediários" (midpoint) e "pontos finais" (endpoint), ou ambos, em metodologias integradas de AICV. De forma geral, em metodologias midpoint, um número maior de categorias de impacto é determinado, e os resultados são mais exatos e precisos comparados com as avaliaçóes de endpoint, as quais consideram normalmente as três áreas de proteção (saúde humana, qualidade do ecossistema e uso de recursos). 
As principais categorias consideradas em uma avaliação de midpoint são: mudanças climáticas, destruição da camada de ozônio, toxicidade humana, inorgânicos respiratórios, radiação ionizante, formação fotoquímica de ozônio, acidificação, eutrofização, ecotoxicidade, uso do solo e esgotamento de recursos.

Dependendo do objetivo do estudo e da natureza do sistema estudado, a inclusão de categorias ou fatores de impacto faltantes, que sejam relevantes para os resultados finais, pode ser necessária. Além disso, para estudos comparativos de ACV, também é importante que a adequação de metodologias genéricas de AICV seja discutida na fase de interpretação do estudo.

A normalização, agrupamento e ponderação são estágios opcionais que buscam um resultado completamente agregado.

$\mathrm{Na}$ normalização, os resultados dos indicadores para as diferentes categorias de impacto de danos midpoint ou endpoint são expressos em relação a uma referência comum, pela divisão dos resultados do indicador pelo respectivo valor de referência.

Os valores de referência normalmente utilizados são os resultados do impacto total anual territorial de fluxos elementares em um país, região ou continente, ou de forma global, per capita, por exemplo. Para resultados midpoint a base da normalização é o impacto potencial total, calculado a partir de um inventário anual dos fluxos elementares. Para resultados endpoint, a base da normalização é o dano total causado nas áreas de proteção (saúde humana, qualidade dos ecossistemas, mudanças climáticas e recursos naturais).

$\mathrm{Na}$ ponderação, os resultados dos indicadores para diferentes categorias de impacto ou danos são multiplicados (cada um deles) por um fator de ponderação específico, que tem a intenção de refletir a relevância de diferentes categorias/fatores de impactos dentre as outras.

Conjuntos de ponderação podem ser desenvolvidos por diferentes mecanismos, por formuladores de políticas públicas ou painéis de indústrias, de partes interessadas, de peritos, etc. É importante notar que fatores de ponderação são sempre subjetivos e refletem valores pressupostos. Portanto, após a ponderação, é importante, na interpretação do estudo, deixar claros tais pressupostos e limitaçóes, para que a avaliação dos resultados obtidos seja direcionada e não enganosa. 
As normas NBR ISO 14040 (ABNT, 2009a) e NBR ISO 14044 (ABNT, 2009b) indicam a estrutura metodológica geral das fases para a realização da ACV, assim como da AICV. Contudo, não indicam os métodos para a realização do estudo.

\subsubsection{Metodologias de AICV}

Existem hoje mais de 50 métodos de AICV disponíveis na Europa (EPLCA, 2010), conforme apresentado na Tabela 1. São técnicas específicas referentes aos impactos ambientais que integram o escopo das avaliaçóes efetuadas em diferentes regiôes. No entanto, verifica-se a existência de esforços no sentido de ampliar o escopo de aplicação desse instrumento, levando em consideração as diferenças espaciais regionais dos demais ambientes mundiais.

Tabela 1. Países de origem das principais metodologias de AICV.

\begin{tabular}{lll}
\hline Metodologia & Desenvolvida por & País de origem \\
\hline CML & CML & Holanda \\
\hline ECo-Indicator 99 & PRé & Holanda \\
\hline EDIP97 - EDIP2003 & DTU & Dinamarca \\
\hline EPS 2000 & IVL & Suécia \\
\hline Impact 2002+ & EPFL & Suíça \\
\hline LIME & AIST & Japão \\
\hline LUCAS & CIRAIG & Canadá \\
\hline ReCiPe & RUN + Pré + CML + RIVM & Holanda \\
\hline Swiss Ecoscarcity 07 & E2+SEU-services & Suíça \\
\hline TRACI & US EPA & Estados Unidos \\
\hline MEEuP & VhK & Holanda \\
\hline Impact World + & DTU, CIRAIG, EPFL & Cooperação global \\
\hline
\end{tabular}

Fonte: EC-JRC (2010b).

Os principais métodos amplamente utilizados na fase de avaliação de impactos da ACV são: Eco Indicator 99, EDIP 97, EDIP 2003, (Dutch) Handbook on LCA (CML2002), TRACI, EPS 2000, Impact 2002(+), LIME, Swiss Ecoscarcity (Ecopoints 2006), ReCiPe, MEEuP e Impact World +. Esses métodos são majoritariamente desenvolvidos dentro do escopo regional europeu, no entanto, verifica-se a existência de esforços no sentido de ampliar o escopo de aplicação desse instrumento, considerando as diferenças espaciais regionais dos demais ambientes mundiais. 
Nesta etapa, passaremos então a uma descrição sintética de algumas dessas principais metodologias de AICV (as mais utilizadas em estudos envolvendo sistemas construtivos), tomando como base sua estruturação geral, contexto, e, principalmente, suas particularidades, de forma que se possa, assim, estabelecer mais claramente as diferenças e similaridades entre elas.

\subsubsection{CML 2002 (GUINÉE et al., 2002)}

Metodologia holandesa de avaliação midpoint, a CML busca as melhores práticas para os indicadores de operacionalização midpoint da série de normas ISO 14040. Sua validade regional é global, exceto no que se refere à acidificação e formação de foto-oxidantes (para os quais a abrangência é apenas para a Europa).

Para todas as categorias de emissão, princípios semelhantes são utilizados com respeito, por exemplo, à manipulação de tempo, espaço e não linearidades. Para cada indicador, fatores de normalização específicos são calculados.

As principais particularidades dessa metodologia, segundo o ILCD Handbook (EC-JRC, 2010b) são:

- Fundamentação científica de apoio a todas as escolhas importantes;

- Fornecimento de fatores alternativos de AICV para análises de sensibilidade em cada categoria de impacto;

- Distinção entre categorias de impacto básicas, específicas do estudo e outras;

- A maioria de suas categorias de impacto já foi descrita em artigos científicos;

- Princípios para AICV desenvolvidos juntamente com os princípios para os outros elementos da metodologia de ACV.

\subsubsection{ECo-indicator 99 (GOEDKOOP; SPRIENSMA, 2000)}

Eco-indicador 99 é uma metodologia endpoint desenvolvida com o objetivo de simplificar a interpretação e ponderação dos resultados. Uma das aplicações previstas é o cálculo de pontuaçôes de eco-indicadores de um único ponto que 
podem ser usados por projetistas no dia-a-dia para tomada de decisão, mas também como um método de avaliação de impacto geral na ACV.

Possui categorias de impacto globais para mudanças climáticas, destruição do ozônio e recursos. Para outras categorias de impacto, todas as emissões são assumidas a ter lugar na Europa.

Todos os mecanismos ambientais são marginais. $\mathrm{O}$ uso de apenas três indicadores por categoria de impacto também força a harmonização em modelos.

A normalização não é feita por categoria de impacto, mas por área de proteção (saúde humana, qualidade dos ecossistemas, mudanças climáticas e recursos naturais).

As principais particularidades dessa metodologia, segundo o ILCD Handbook (EC-JRC, 2010b), são:

- O uso de três perspectivas para criar conjuntos consistentes de escolhas subjetivas a respeito da perspectiva temporal aplicada, a importância da capacidade de gerenciamento, o papel do desenvolvimento tecnológico futuro e do nível de mecanismos de causa-efeito;

- O uso consistente, em uma abordagem totalmente integrada, da mesma unidade de resultado para todas as categorias de impacto, resultando em danos para a saúde humana, ecossistemas ou recursos, respectivamente;

- Evita a dupla contagem da categoria de uso do solo com ecotoxicidade e eutrofização;

- A fase de normalização é baseada em indicadores endpoint.

\subsubsection{EDIP 1997-2003 (WENZEL et al., 1997; POTTING; HAUSCHILD, 2005)}

A parte de AICV de EDIP97 (WENZEL et al., 1997) é composta por categorias clássicas relacionadas com categorias de impacto de emissóes midpoint, bem como recursos e ambiente de trabalho. Inclui normalização e ponderação dos impactos ambientais com base em metas de políticas ambientais. EDIP2003 (POTTING; HAUSCHILD, 2005) é uma continuação da metodologia com a inclusão da avaliação de exposição com base em informaçóes regionais de AICV relacionado com categorias de impacto de emissóes não globais midpoint. As principais particularidades dessa metodologia são (EC-JRC, 2010b): 
- O aquecimento global tem fatores de caracterização para todos os compostos orgânicos voláteis de origem petroquímica;

- Fatores de caracterizaçáa de destruiçáa do ozônio têm horizontes de tempo mais curtos ( 5 e 20 anos) de potencial relevância, uma vez que o principal problema com a destruição do ozônio estratosférico será nas próximas décadas;

- Ambiente de trabalho diferenciado;

- Revisão externa por pares de todos os modelos de caracterização.

\subsubsection{IMPACT 2000+ (JOLLIET et al., 2003)}

Esta metodologia propõe uma implementação viável de abordagem combinada midpointlendpoint, ligando todos os tipos de resultados de ICV (fluxos elementares e outras intervençôes) com 14 categorias midpoint e quatro endpoint. Traz novos conceitos e métodos, com base em abordagens existentes, para garantir que melhor se ajustem ao escopo comparativo de AICV, especialmente para a avaliação comparativa de toxicidade humana e eco-toxicidade. Foi desenvolvido em colaboração com os desenvolvedores do método LIME e outras categorias midpoint a partir da adaptação de métodos existentes (Eco-indicador 99 e CML, 2002). Todos os impactos midpoint são expressos em unidades de uma substância de referência e relacionados com as quatro categorias de impacto: saúde humana, qualidade do ecossistema, alterações climáticas e recursos. A normalização pode ser realizada no nível midpoint ou endpoint.

As principais particularidades dessa metodologia, segundo o ILCD Handbook (EC-JRC, 2010b), são:

- Novos conceitos e métodos de avaliação comparativa melhorada de toxicidade humana e efeitos de ecotoxicidade (ambos são baseados em respostas médias em vez de suposiçóes conservadoras) foram desenvolvidos para IMPACT $2002+$;

- Para categorias recursos, o conceito de energia é excedente, de acordo com Muller Wenk (1994); mas, para os combustíveis fósseis, é a soma da energia primária e excedente.Desenvolvimentos têm sido realizados sobre a exposição do ar interior e impactos diretos de pesticidas. 


\subsubsection{ReCiPe (GOEDKOOP et al., 2008)}

O método ReCiPe é uma continuação dos métodos Eco-indicador 99 e CML 2002. Ele integra e harmoniza as abordagens midpoint e endpoint em uma estrutura consistente. Embora inicialmente a integração dos métodos fosse o objetivo, todas as categorias de impacto têm sido remodeladas e atualizadas (exceto radiação ionizante). $\mathrm{O}$ método não foi publicado como um único documento ainda, mas categorias de maior impacto têm sido descritas em periódicos científicos. Para todas as categorias de emissões, princípios e escolhas semelhantes são usados. Todos os impactos são marginais. Todas as categorias de impacto da mesma área de proteção têm a mesma unidade de indicador. Os mesmos mecanismos ambientais são usados para cálculos de midpoint e endpoint.

As principais particularidades dessa metodologia, segundo o ILCD Handbook (EC-JRC, 2010b), são:

- Uso consistente de midpoints e endpoints no mesmo mecanismo ambiental. Pontos médios são escolhidos o mais próximo possível aos resultados de ICV (menor incerteza do indicador);

- Abordagem marginal consistente;

- Subcompartimentos de ar rural e urbano aplicados a fatalidades e modelo de exposição para a toxicidade humana.

- A maioria das categorias de impacto já foi descrita em artigos científicos.

\subsubsection{Ecological Scarcity Method / Ecopoints 2006 (MULLER- WENK, 1994)}

O método de Ecological Scarcity - às vezes chamado Swiss Ecoscarcity ou Swiss Ecopoints - permite uma ponderação comparativa e agregação de várias intervençóes ambientais pelo uso dos chamados eco-fatores.

O método fornece esses fatores de ponderação para emissóes diferentes em água, ar e solo superficial ou águas subterrâneas, bem como para o uso dos recursos energéticos. Os fatores ecológicos baseiam-se nos fluxos anuais reais (fluxos atuais) e no fluxo anual, considerado como crítico (fluxos críticos), em uma área definida (país ou regiáo). Os eco-fatores foram originalmente desenvolvidos para a área da Suíça e, mais tarde, conjuntos de eco-fatores 
também foram disponibilizados para outros países, como Bélgica e Japão. O método foi desenvolvido para avaliaçóes ambientais padrão, por exemplo, de produtos ou processos específicos.

\subsubsection{TRACI (BARE et al., 2003)}

Foi desenvolvido pela EPA dos EUA como um método midpoint que representa as condiçóes ambientais nos EUA como um todo ou por estado. Durante o desenvolvimento do TRACI, a coerência com os pressupostos de modelagem anteriores foi importante para cada categoria de impacto. Para categorias como a acidificação e formação de fumaça, modelos empíricos detalhados norte-americanos, como os desenvolvidos pelo United States National Acid Precipitation Assessment Program e California Air Resources Board, permitiram a inclusão das abordagens mais sofisticadas para localizaçóes específicas e fatores de caracterização para localização específica. Escolhas são minimizadas pela utilização de níveis midpoint. Nos quais as escolhas necessárias são feitas com base nas políticas da EPA.

As principais particularidades dessa metodologia, segundo o ILCD Handbook (EC-JRC, 2010b), são:

- Esse método é apoiado pela EPA dos EUA e é especialmente relevante para as emissóes que ocorrem como parte de ciclos de vida do produto nos EUA.

- Para a acidificação, eutrofização e formação de fumaça, fatores de caracterização regionais específicos (por estado) estão disponíveis.

\subsubsection{Impact World + (IMPACT WORLD +, 2012)}

A maioria dos impactos modelados na ACV é regional ou local, no entanto, as metodologias de ACV atualmente oferecem fatores de caracterização genéricos, os quais representam condições médias para uma regiâo específica, como um país ou continente, sem levar em consideração a variabilidade espacial desses impactos.

A metodologia IMPACT World+ está sendo desenvolvida como resposta à necessidade de regionalização da avaliação de impacto. Essa metodologia cobre todo o mundo, implementando abordagens de modelagem de caracterização 
desenvolvidas como uma atualização conjunta dos métodos IMPACT 2002+, EDIP e LUCAS.

Informaçôes relacionadas à variabilidade espacial e modelagem de incertezas estão inclusas, e a metodologia oferece fatores de caracterização para cada continente, permitindo a avaliação regional de qualquer emissão/consumo de recursos que seja georreferenciado, como fornecido pelo banco de dados Ecoinvent, e a determinação da incerteza relativa a uma emissão de localização desconhecida, associando a variabilidade geográfica correspondente de cada fator de caracterização em uma determinada escala geográfica. A Figura 10 mostra a estrutura do método Impact World+.

\subsection{Interpretação de Ciclo de Vida}

A fase de interpretação de uma $\mathrm{ACV}$ tem dois objetivos principais que se diferenciam fundamentalmente:

- Durante os passos iterativos da ACV e para todos os tipos de entregas, a fase de interpretaçáo serve para orientar o trabalho no sentido de melhorar os modelos de ICV para atender as necessidades derivadas do objetivo do estudo.

- Se as etapas iterativas da ACV resultaram no modelo e resultados finais de ICV e, especialmente, para estudos comparativos de ACV, a fase de interpretação serve para tirar conclusôes robustas e - muitas vezes recomendaçốes.

A interpretação de ciclo de vida é a fase da ACV em que os resultados das demais etapas são então considerados coletivamente e analisados sob a luz do rigor, completeza e precisão alcançados para os dados utilizados, assim como também para as suposiçóes que tenham sido assumidas durante o estudo de ACV/ICV. Os resultados finais da interpretação podem ser conclusôes e recomendaçôes, as quais devem respeitar as intençóes e restriçóes do objetivo e escopo definidos para o estudo. Isso está especialmente relacionado com a adequação da unidade funcional e fronteiras do sistema, assim como a qualidade dos dados obtidos em relação ao objetivo. A interpretaçáo deve apresentar os resultados da ACV de forma inteligível e ajudar o usuário do estudo a avaliar a robustez das conclusóes e compreender as limitaçóes potenciais do estudo. 
A fase de interpretação é composta de três etapas:

- Identificação das questóes significativas, como processos elementares, parâmetros, suposiçóes e fluxos elementares;

- Tais questôes devem ser avaliadas considerando sua sensibilidade ou influência nos resultados gerais do estudo de ACV, etapa que inclui avaliaçôes de completeza e consistência;

- Os resultados da avaliação devem ser usados na formulação de conclusôes e recomendaçôes a partir do estudo de ACV.

Em casos em que o estudo envolve comparaçóes entre dois ou mais sistemas, consideraçôes adicionais deverão ser incluídas na interpretação.

\subsubsection{Identificação de Questões Significativas}

O objetivo desse primeiro elemento da interpretação é analisar e estruturar os resultados das fases anteriores da ACV de forma a identificar as questóes significativas. Há dois aspectos inter-relacionados das questóes significativas:

- Primeiramente, há os principais contribuintes para os resultados da $\mathrm{AICV}$, isto é, os estágios, processos e fluxos elementares mais relevantes do ciclo de vida, assim como as categorias de impacto mais relevantes;

- Em segundo lugar, há as principais escolhas que podem ter influência potencial na precisão dos resultados finais da $\mathrm{ACV}$, como escolhas metodológicas, suposiçóes, dados utilizados para determinar os inventários dos processos, metodologias utilizadas para a AICV, assim como fatores de normalização e ponderação opcionalmente utilizados.

\subsubsection{Análise de Contribuição}

A análise de contribuição pode ser requerida para várias aplicaçôes:

- Identificar a necessidade de coleta de novos dados ou de melhoria de qualidade de dados por meio da quantificação da completeza do inventário;

- Concentrar mais esforços na coleta de dados sobre os processos que mais contribuíram e intervençôes individuais de fluxos elementares; 
- Concentrar esforços em ecodesign e melhoria/desenvolvimento do produto nos processos que mais contribuíram e em intervençóes individuais de fluxos elementares;

- Informar a parcela de contribuição interna e externa para o impacto ambiental global às partes interessadas;

- Contribuir para o controle de qualidade interno durante o trabalho de ACV, investigando a verossimilhança qualitativa e quantitativa dos resultados detalhados da análise de contribuição.

\subsubsection{Avaliação}

A avaliação é realizada no intuito de estabelecer fundamentos para se obter conclusões e fornecer recomendaçôes durante a interpretação dos resultados de ICV/ACV. Tal avaliação envolve a verificação de completeza, a verificação de sensibilidade e a verificação de consistência.

O resultado da avaliação é crucial para dar robustez às conclusôes e recomendaçóes do estudo e precisa ser apresentado de forma que dê uma compreensão clara dos resultados. Usando os mesmos métodos e abordagens como a avaliação final do estudo de ACV, a avaliação é também usada durante o desenvolvimento do estudo para analisar a completeza, o rigor, a precisão e a consistência alcançados. Isso serve para identificar a necessidade de dados adicionais ou melhores, assim como revisão de suposiçôes feitas e outras escolhas metodológicas.

\subsubsection{Verificação de Completeza}

Verificações de completeza no inventário são realizadas de forma a determinar em que grau a lista de dados está completa e se os critérios de corte foram cumpridos. Caso os critérios de corte não tenham sido obedecidos, dados adicionais ou melhores deverão ser usados para satisfazer o objetivo e escopo da ACV.

Durante a execução da verificação de completeza, fatores de AICV e fluxos elementares faltantes devem ser quantitativamente considerados. Em casos nos quais os critérios de corte não puderem ser atingidos, as definiçôes de objetivo e escopo deverão ser ajustadas para acomodar tal lacuna de completeza, o que 
pode significar que questóes originais do objetivo não poderão ser respondidas ou que os dados obtidos não atingiram a qualidade requerida.

Como regra geral, é recomendada a inclusão do maior número de fluxos elementares possível no inventário para permitir que o usuário realize uma avaliação de impacto detalhada. É importante notar que a porcentagem de completeza alcançada não pode ser mal interpretada, como indicando exatos $100 \%$ de completeza. No entanto, a completeza alcançada indica o valor real aproximado.

$\mathrm{Na}$ prática, essa questão pode ser razoavelmente abordada da seguinte forma: depois da modelagem do sistema com os dados disponíveis, para todas as lacunas de informação, um valor/fluxo "bem aproximado" deverá ser identificado pelo julgamento de especialistas. Isso se relaciona a todos os tipos de lacunas de informaçóes e dados, especialmente:

- Tipos e quantidades de dados de fluxos inicialmente faltantes;

- Composiçóes de elementos e conteúdo de energia de todos os fluxos que contribuam de forma relevante para a massa total dos fluxos;

- Custos de todos os bens e serviços que contribuam de forma relevante para o custo e valor total de produçáo;

- Impacto ambiental dos dados faltantes para bens e serviços consumidos.

As mais problemáticas são as lacunas qualitativas, ou seja, a falta de conhecimento da ocorrência de um fluxo. Para emissóes, provisôes legais de qualquer natureza que visem à apresentação de relatórios, medição ou à redução dessas emissões são um meio adequado para detectar a sua existência e relevância potencial.

Para obtençáo dos valores de completeza atingidos, provisórios ou finais, uma porcentagem de cobertura de dados (com qualidade, no mínimo, de dados estimados) é calculada. Esse procedimento utiliza o valor aproximado de $100 \%$ do modelo de sistema completo, incluindo dados de baixa qualidade como referência.

\subsubsection{Verificação de Sensibilidade}

A verificação de sensibilidade tem o objetivo de avaliar a confiabilidade dos resultados, conclusóes e recomendaçóes do estudo de ACV. Julgamento de 
especialistas e experiências anteriores contribuem para a análise de sensibilidade. Análise de cenários e cálculos de incerteza são os métodos quantitativos para apoiá-la. Na fase de interpretação, a análise de sensibilidade é utilizada juntamente com informaçóes sobre as incertezas de questóes significativas dentre os dados de inventário, de avaliação de impacto e suposiçóes e escolhas metodológicas para avaliar a confiabilidade dos resultados finais, conclusóes e recomendaçóes baseadas em tais resultados.

A análise de sensibilidade deve verificar as limitações na adequação de escolhas de escopo em relação ao objetivo do estudo, assim como o estabelecimento de conclusóes e recomendaçóes, especialmente:

- Identificação dos sistemas a serem estudados;

- Identificação das funçóes e unidades funcionais do sistema ou, em caso de estudos comparativos, dos sistemas;

- Identificação da modelagem e abordagem de ICV apropriadas a serem aplicadas;

- Identificação das fronteiras do sistema e quantificação do critério de corte;

- Seleção das categorias de impacto e métodos de AICV a serem aplicados;

- Identificação da abordagem a ser usada para interpretação;

- Identificaçáo dos dados de ICV e requisitos de qualidade dos dados, incluindo a aplicabilidade dos dados de inventário nos métodos de AICV selecionados;

- Seleção de métodos de normalização e ponderação, caso sejam inclusos no estudo;

- Tipos de suposiçóes e relevância das escolhas de valores feitas;

- Identificação das limitaçôes aplicáveis ao uso e/ou interpretação dos resultados.

Em relação a questôes de objetivo e escopo, a verificação de sensibilidade pode ser feita pelo cálculo e comparação de cenários, especialmente para diferentes abordagens de alocação na fase de inventário. Para outros itens, isso 
pode ser feito por análise qualitativa baseada no julgamento de especialistas e apoiada em experiências anteriores.

A análise de sensibilidade deve verificar a existência de limitaçóes na adequação do trabalho de ICV em relação ao objetivo e escopo do estudo, assim como estabelecer conclusôes e recomendaçôes. Isso se refere, especialmente, à coleta e seleção adequada de dados de inventário em relação à:

- Representatividade tecnológica, geográfica e temporal para o sistema analisado;

- Completeza do inventário em relação às categorias de impacto escolhidas e quantitativamente relevantes;

- Precisão dos valores e parâmetros de inventário, devido à incerteza dos dados primários utilizados.

A verificação pode ser feita por análise de cenários e/ou ser acompanhada por um cálculo de incerteza.

Em relação à AICV, a verificação de sensibilidade pode ser realizada por uma análise de cenários, aplicando-se diferentes metodologias de AICV possíveis. Isso pode ser acompanhado por um cálculo de incertezas nos resultados da AICV.

Devido ao caráter iterativo da $\mathrm{ACV}$, a análise de sensibilidade pode ainda ser utilizada como um elemento integrado nas iteraçóes do estudo, incorporando a coleta de dados de inventário, a avaliação de impacto e a determinação de fronteiras do sistema. Os resultados das análises de sensibilidade anteriores poderão então ser usados como ponto de partida para a verificação de sensibilidade da interpretação.

\subsubsection{Verificação de Consistência}

A verificação de consistência é realizada para investigar se as suposições, métodos e dados foram aplicados de forma consistente no decorrer do estudo de ACV. Essa verificação é aplicável ao ciclo de vida de um sistema analisado, assim como entre sistemas comparados.

Questôes metodológicas de relevância são, especialmente, a modelagem e abordagem de ICV, como também o estabelecimento de fronteiras do sistema, excesso de dados, aplicação consistente da avaliação de impacto e 
outras suposiçóes. $\mathrm{Na}$ fase de inventário, as principais questóes são aquelas relacionadas à consistência da representatividade temporal, geográfica e tecnológica dos dados, à adequação do processo de unidade escolhido ou à capacidade dos resultados do ICV representarem os processos do sistema, assim como a completeza e precisão dos dados. Questôes relacionadas à avaliação de impacto são aquelas referentes à aplicação consistente dos elementos da AICV, incluindo os fatores de normalização e ponderação.

\subsubsection{Conclusões, Limitações e Recomendações}

Integrando o resultado dos outros elementos da fase de interpretação e baseando-se nas principais conclusóes das fases anteriores da ACV, os elementos finais da interpretação são o estabelecimento de conclusôes, identificação das limitaçóes do estudo e desenvolvimento de recomendaçóes para o público-alvo, de acordo com a definição de objetivo e aplicaçôes previstas dos resultados.

As limitaçôes mais frequentemente notáveis para estabelecimento de conclusôes significativas são:

- As fronteiras do sistema/critérios de corte;

- Qualidade e consistência alcançadas para os dados de ICV, conforme o objetivo do estudo;

- Incertezas das metodologias de AICV;

- Suposições da fase de definição de objetivo;

- Outras limitaçóes metodológicas ou específicas do estudo.

Se as conclusóes forem consistentes com os requisitos, elas podem ser relatadas como conclusôes finais, caso contrário, essas precisarão ser reformuladas e verificadas novamente. Quaisquer limitaçóes do estudo dentro do objetivo e escopo devem ser listadas, e então avaliadas, para cada uma, o tipo e a magnitude das consequências que elas têm para as conclusóes e aplicaçóes pretendidas.

Em estudos que envolvem a comparação de sistemas, a interpretação deve considerar alguns pontos adicionais, para assegurar conclusóes justas e relevantes a partir do estudo: 
- Questóes significativas devem ser determinadas para cada um dos sistemas, com atenção especial para questôes que venham a diferir entre os sistemas e que tenham potencial de mudar conclusôes da comparação. Tais conclusões precisam ser eliminadas se possível ou, caso contrário, consideradas na formulação do relatório;

- Caso uma análise de incerteza foi realizada para investigar se a diferença entre dois sistemas é estatisticamente significativa, tal análise deve ser realizada nas diferenças entre os sistemas, levando em conta variaçóes entre processos;

- A verificação de consistência aborda o tratamento consistente de questôes-chave nos diferentes sistemas e é fundamental para assegurar uma comparação justa.

Recomendaçóes baseadas nas conclusóes finais do estudo de ACV devem ser lógicas, razoáveis e plausíveis, além de estritamente relacionadas com as aplicaçóes pretendidas, conforme definido no objetivo do estudo.

\subsubsection{Comunicação}

A forma e níveis de apresentação de relatórios dependem de três fatores primários:

- Os tipos de entregas do estudo;

- O objetivo e aplicaçóes pretendidas do estudo e do relatório;

- O público-alvo (especialmente audiência técnica ou não técnica e interna ou de terceira parte/pública).

Independentemente se os resultados da AICV sejam publicados em forma de relatório ou conjunto de dados, por razóes de transparência, eles devem ser acompanhados pelos resultados do ICV. Existem três tipos de relatórios:

- Relatório para uso interno e que não deverá ser divulgado a nenhuma parte externa à instituiçáo que encomendou/financiou o estudo ou que realizou o trabalho de $\mathrm{ACV}$;

- Relatório para documentar e/ou comunicar os resultados da ACV no intuito ser apresentados a uma terceira parte; 
- Estudo que envolve uma comparação de produtos cujos resultados deverão ser divulgados ao público.

- O relatório de um estudo de ACV deve ser composto pelos seguintes elementos:

- Sumário Executivo (para audiência não técnica): deve incluir, pelo menos, elementos-chave do objetivo e o escopo do sistema estudado. Os principais resultados das fases de ICV e AICV devem ser apresentados de maneira a assegurar o uso apropriado da informação, assim como afirmaçóes relevantes sobre qualidade dos dados, suposiçóes e julgamentos de valores.

- Sumário Técnico (para audiência técnica/praticantes de ACV): deve incluir, no mínimo, o objetivo,o escopo com limitações e as suposiçóes relevantes, além de um diagrama geral de fluxos do sistema estudado. Deve indicar claramente, ademais, o que foi atingido pelo estudo. Os principais resultados das fases de ICV e AICV devem ser apresentados de maneira a assegurar o uso apropriado da informação, assim como afirmaçóes relevantes sobre qualidade dos dados, suposiçóes e julgamentos de valores.

- Parte principal (para praticantes de ACV): Todas as fases do estudo de ACV devem ser apresentadas de forma detalhada e transparente, incluindo o objetivo completo do estudo, o escopo detalhado, os resultados da análise de inventário, a avaliação de impacto de ciclo de vida, os resultados, a interpretação dos dados, as conclusóes e recomendações.

- Anexos (para praticantes de ACV): Os anexos servem para documentar elementos de natureza mais técnica, que poderiam interromper o fluxo das partes principais do relatório de ACV, mas que devem ser usados como referência, como, por exemplo, as memórias de cálculo dos inventários e AICV.

- Relatório confidencial: deve conter todos os dados e informaçóes confidenciais que não podem ser disponibilizados publicamente. Esse relatório deve ser disponibilizado para revisores críticos, sob condiçóes de confidencialidade. 


\subsubsection{Revisão Crítica}

A revisão crítica deve assegurar, entre outras coisas, se:

Os métodos utilizados pela AICV são consistentes em relação à documentação de orientação e também com as normas NBR ISO 14040 (2009a) e NBR ISO 14044 (2009b);

- Os métodos utilizados para a ACV são válidos científica e tecnicamente;

- Os dados usados são apropriados em relação ao objetivo do estudo;

- A interpretação reflete as limitações identificadas e o objetivo do estudo;

- O relatório do estudo é transparente e consistente.

- A etapa de revisão crítica é de extrema importância para assegurar a confiabilidade e robustez de um estudo de ACV, uma vez que, sendo avaliado por terceira parte, possíveis falhas de documentação ou de definiçôes e análises do estudo podem ser identificadas e sanadas previamente à publicação do relatório para audiência externa. A importância é ainda maior em se tratando de estudos comparativos a serem divulgados ao público, nos quais se deve evitar ao máximo a possibilidade de publicação de resultados e conclusões enganosos.

\section{Referências Bibliográficas}

ASSOCIAÇÃO BRASILEIRA DE NORMAS TÉCNICAS (ABNT). NBR ISO 14040 Gestão Ambiental - Avaliação do Ciclo de Vida: princípios e estrutura. Rio de Janeiro, 2009a.

ASSOCIAÇÃO BRASILEIRA DE NORMAS TÉCNICAS (ABNT). NBR ISO 14044 Gestão Ambiental - Avaliação do ciclo de vida: requisitos e orientaçốes. Rio de Janeiro, 2009b.

ASSOCIATION FRANÇAISE DE NORMALISATION (AFNOR). Norme NF P01-010 - Qualité environnementale des produits de construction, Déclaration des caractéristiques environnementales et sanitaires des produits de construction et de leur contribution aux impacts environnementaux d'un ouvrage donné. Paris, 2004.

BARE, J. C.; NORRIS, G. A.; PENNINGTON, D. W.; MCKONE, T. TRACI: The Tool for the Reduction and Assessment of Chemical and Other Environmental Impacts. Journal of Industrial Ecology 6(3), pp. 49-78. 2003. 
BRIBIÁN, I. Z.; USÓN, A. A.; SCARPELLINI, S. Life cycle assessment in buildings: Stateof-the-art and simplified LCA methodology as a complement for building certification. Building and Environment, vol. 44, pp. 2510-2520. 2009.CHEVALIER, J.L.; LE TENO, J.F. Requirements for an LCA-based model for the evaluation of the environmental quality of building products. Building and Environment, vol. 31(5), pp. 487-91. 1996.

ERLANDSSON, M.; BORG, M. Generic LCA-methodology applicable for buildings, constructions and operation services - today practice and development needs. Building and Environment, vol. 38, pp. 919-938. 2003.

EUROPEAN COMMISSION: JOINT RESEARCH CENTRE OF THE (EC-JRC). International Reference Life Cycle Data System (ILCD) Handbook - General guide for Life Cycle Assessment - Detailed guidance. 2010a.

EUROPEAN COMMISSION: JOINT RESEARCH CENTRE OF THE (ECJRC). International Reference Life Cycle Data System (ILCD) Handbook - Analysis of existing Environmental Impact Assessment Methodologies for use in Life Cycle AssessmentBackground document. 2010b.

European Platform on Life Cycle Assessment (EPLCA). List of tools: Internet site developed by the European Commission. Direction Generale. Joint Research Centre. Institute for Environment and Sustainability, 2010. Disponível em http://lca.jrc.ec.europa.eu/ lcainfohub/toolList.vm. Acesso em: 01 abr. 2013.

FRANKE, C. Ciclo de vida de produtos. Trabalho desenvolvido entre a Universidade Técnica de Berlin (TUBerlin) e o Grupo de Adequação Ambiental em Manufatura (AMA). Disponível em http://www.numa.org.br, 2004.

GOEDKOOP, M.; HEIJUNGS, R.; HUIJBREGTS, M.; DE SCHRYVER, A.; STRUIJS, J.; VAN ZELM, R. ReCiPe 2008 - A life cycle impact assessment method which comprises harmonised category indicators at the midpoint and the endpoint level. Available at: http://lcia.wik.is. 2008.

GOEDKOOP, M.; SPRIENSMA. Eco-indicator 99, a damage-oriented method for lifecycle Impact assessment, methodology report. 2000.

GUINÉE, J. B.; GORRÉE, M.; HEIJUNGS, R.; HUPPES, G.; KLEIJN, R.; KONING, A.; VAN OERS, L.; SLEESWIJK, A. W.; SUH, S.; UDO DE HAES, H. A.; DE BRUIJN, J. A.; VAN DUIN, R.; HUIJBREGTS, M. A. J. Handbook on Life Cycle Assessment: Operational Guide to the ISO Standards. Series: Eco-efficiency in industry and science. Kluwer Academic Publishers. Dordrecht, 2002.

IMPACT WORLD +. Impact World +: Presentation. Disponível em: http://www. impactworldplus.org/en/presentation.php. Acesso em: 19 out. 2012.

JOHN, V. M.; OLIVEIRA, D. P.; AGOPYAN, V.. Critérios de sustentabilidade para seleção de materiais e componentes - uma perspectiva de sustentabilidade para países em desenvolvimento. Journal of Building Environment, 2006.

JOLLIET, O., MARGNI, M., CHARLES, R., HUMBERT, S., PAVET, J., REBITZER, G.; ROSEMBAUM, R. Impact 2002: A New Life Cycle Impact Assessment Methodology. Int J. of LCA 8 (6) 324-330. 2003. 
LEMAIRE, S.; CHEVALIER, J.; GUARRACINO, G.; HUMBERT, H. Using the French EPDs to compare and to choose building products. CIB World Building Congress 2007: Construction for Development, Cape Town, 21-25 May 2007.

MULLER-WENK, R. The Ecoscarcity Method as a Valuation Instrument within the SETAC - Framingwork, in: Udo de Haes/Jensen/Klöpffer/Lindfors (Ed.): Integrating Impact Assessment into LCA, SETAC-Europe, Brussels 1994, p. 115-120.

POTTING, J.; HAUSCHILD, M. Spatial differentiation in life cycle impact assessmentthe EDIP2003 methodology. Environmental News n. 80. The Danish Ministry of the Environment, Environmental Protection Agency, Copenhagen, 2005.

SILVA, V. G. Uso de Materiais e Sustentabilidade. Revista Sistemas Prediais (Online), julho, 2007. Disponível em <http://www.nteditorial.com.br/revista/Materias/index. asp?RevistaID1=7\& Edicao=22\&id=200\&TopicoID=318>. Acesso em: 10 ago. 2009.

SOARES, S. R.; SOUZA, D. M.; PEREIRA, S. W. Avaliação do ciclo de vida no contexto da construção civil. Coletânea Habitare - vol. 7 - Construção e Meio Ambiente. Porto Alegre, 2006.

VERBEECK, G.; HENS, H. Life cycle inventory of buildings: A calculation method. Building and Environment, vol. 45, pp. 1037-1041. 2010a.

VERBEECK, G.; HENS, H. Life cycle inventory of buildings: A contribution analysis. Building and Environment, Volume 45, Issue 4. 2010b.

WENZEL, H.; HAUSCHILD, M.; ALTING, L. Environmental Assessment of Products. Bonton/Dordrecht/London: Kluwer Academic Publishers. v. 1 e 2. 1997. 
